\title{
Insights into the genes involved in the ethylene biosynthesis pathway in Arabidopsis thaliana and Oryza sativa
}

\author{
Mostafa Ahmadizadeh ${ }^{1}$, Jen-Tsung Chen², Soosan Hasanzadeh ${ }^{3}$, Sunny Ahmar ${ }^{4}$ and Parviz Heidari ${ }^{*}$ (D)
}

\begin{abstract}
Background: Ethylene is a gaseous plant hormone that acts as a requisite role in many aspects of the plant life cycle, and it is also a regulator of plant responses to abiotic and biotic stresses. In this study, we attempt to provide comprehensive information through analyses of existing data using bioinformatics tools to compare the identified ethylene biosynthesis genes between Arabidopsis (as dicotyledonous) and rice (as monocotyledonous).

Results: The results exposed that the Arabidopsis proteins of the ethylene biosynthesis pathway had more potential glycosylation sites than rice, and 1-aminocyclopropane-1-carboxylate oxidase proteins were less phosphorylated than 1aminocyclopropane-1-carboxylate synthase and S-adenosylmethionine proteins. According to the gene expression patterns, S-adenosylmethionine genes were more involved in the rice-ripening stage while in Arabidopsis, ACS2, and 1aminocyclopropane-1-carboxylate oxidase genes were contributed to seed maturity. Furthermore, the result of miRNA targeting the transcript sequences showed that ath-miR843 and osa-miR1858 play a key role to regulate the posttranscription modification of S-adenosylmethionine genes in Arabidopsis and rice, respectively. The discovered cis- motifs in the promoter site of all the ethylene biosynthesis genes of $A$. thaliana genes were engaged to light-induced response in the cotyledon and root genes, sulfur-responsive element, dehydration, cell cycle phase-independent activation, and salicylic acid. The ACS4 protein prediction demonstrated strong protein-protein interaction in Arabidopsis, as well as, SAM2, Os04T0578000, Os01T0192900, and Os03T0727600 predicted strong protein-protein interactions in rice.
\end{abstract}

Conclusion: In the current study, the complex between miRNAs with transcript sequences of ethylene biosynthesis genes in A. thaliana and O. sativa were identified, which could be helpful to understand the gene expression regulation after the transcription process. The binding sites of common transcription factors such as MYB, WRKY, and ABRE that control target genes in abiotic and biotic stresses were generally distributed in promoter sites of ethylene biosynthesis genes of $A$. thaliana. This was the first time to wide explore the ethylene biosynthesis pathway using bioinformatics tools that markedly showed the capability of the in silico study to integrate existing data and knowledge and furnish novel insights into the understanding of underlying ethylene biosynthesis pathway genes that will be helpful for more dissection.

Keywords: Cis-acting elements, miRNAs, Post-transcriptions modifications, Ligand binding site, Pathway study

\footnotetext{
* Correspondence: heidarip@shahroodut.ac.ir

${ }^{5}$ Department of Agronomy and Plant Breeding, Faculty of Agriculture,

Shahrood University of Technology, Shahrood, Iran

Full list of author information is available at the end of the article
}

\section{Springer Open}

(๑) The Author(s). 2020 Open Access This article is licensed under a Creative Commons Attribution 4.0 International License, which permits use, sharing, adaptation, distribution and reproduction in any medium or format, as long as you give appropriate credit to the original author(s) and the source, provide a link to the Creative Commons licence, and indicate if changes were made. The images or other third party material in this article are included in the article's Creative Commons licence, unless indicated otherwise in a credit line to the material. If material is not included in the article's Creative Commons licence and your intended use is not permitted by statutory regulation or exceeds the permitted use, you will need to obtain permission directly from the copyright holder. To view a copy of this licence, visit http://creativecommons.org/licenses/by/4.0/. 


\section{Background}

The gas ethylene has been known as a signaling molecule, which regulates stress responses and various developmental processes in plants $[1,2]$, such as a boost of fruit ripening, petal and leaf abscission, flower senescence, incitement of root initiation, and prevention of seedling elongation [3]. Besides, ethylene is produced in response to environmental stresses [3], consisting of wounding [4], flooding [5], bacteria, viruses, fungi, nematodes, and insects [6]. Ethylene has been known as a regulated hormone under stress conditions [7], and several studied ecotypes on stressresponsive genes revealed various basal expression levels [8]. Increment the production of ethylene works as a signaling mechanism with intense physiological outcomes $[1,9$, 10]. Ethylene is synthesized from methionine through its transformation to S-adenosylmethionine that it is converted via the enzyme 1-aminocyclopropane-1-carboxylate synthase into methylthioadenosine and 1-aminocyclopropane1-carboxylic acid (ACC) as the precursor of ethylene [11]. 1-aminocyclopropane-1-carboxylic acid (ACC) is oxidized to $\mathrm{HCN}, \mathrm{CO}_{2}$, and $\mathrm{C}_{2} \mathrm{H}_{4}$ by $\mathrm{ACC}$ oxidase (ACO) [12]. Besides, ACC could be turned from transformation to ethylene by forming the conjugate N-malonyl-ACC [13]. Bleecker et al [11] the 1-aminocyclopropane-1-carboxylate synthase (ACS) activity is regulated at the transcriptional and post-transcriptional levels [1,9]. Owing to the influence of ethylene on senescence and ripening, vast vegetables, fruit, and flowers are lost. Therefore, as a reversible manner, the endeavor has been done to delay or prevent fruit ripening. The activity of ACC synthase has been illustrated with antisense RNA experiments in the role of the rate-limiting phase in ethylene synthesis [14].

The natural diversity of ethylene production suggests that plants by fine-tuning biosynthetic of ethylene and signaling pathways can adapt to different environments. Observation of some stress-responsive genes revealed that this adaptation could be associated to modify the expression of ACS genes via epigenetic modifications $[8,15]$. Moreover, it has been demonstrated that ethylene influence the transcription and translation of many genes which are related to ripening [16], in tomato, at least eight ACS genes have been recognized [17]. The Arabidopsis genome consists of 12 putative ACS-like genes, further, from the ACS genes, $A C S 3$ was identified as pseudogene by a short sequence, besides, ACS12 and ACS10 encode an aminotransferase sans the catalytic activity of ACS [18]. The nine remaining ACS genes encode an ACS proteins group which could be categorized into 3 types, according to the absence or presence of putative phosphorylation sites at the proteins Cterminal extension $[19,20]$. Type- 1 ACS proteins consist of an almost lengthy $\mathrm{C}$-terminal domain that shares the target sites and extremely conserved sequences for a calciumdependent protein kinase (CDPK) and mitogen-activated protein kinase (MAPK) [21-24], while, type-2 have only the anticipated CDPK phosphorylation site. Nonetheless, type-2 ACS proteins consist of an exclusive regulatory motif named a target of ethylene overproducer (ETO1) (TOE) that overlaps by the CDPK target site. Besides, TOE motif mediates interaction by ETO1 E3 ligase, and its two paralogs, ETO1-Like (EOL1 and EOL2), also it is needed for type-2 ACS degradation [24-28]; type-3 ACS contains only a short expansion of amino acids in the C-terminal domain, and no target sites for a MAPK and CDPK [19, 24]. Another plant that was selected for this study was rice as monocotyledonous, rice is the main staple cereal that feeds almost half of the world's population. Owing to the enhancing worldwide demand of the growing population, approximately, $50 \%$ enhance in production of rice will be needed [10]. Rice has the shortest genome of the main cereals and wealthy genetic diversity. Moreover, the sequence of rice whole-genome furnishes the basis to identify the homologous genes for other crops [29, 30]. Its sustainability and productivity are crucially threatened via several biotic and abiotic stresses such as submergence, drought, salinity, and chilling, but ethylene plays an initial role in adopting plants under stress conditions [20,31]. In deep water rice, it has been demonstrated that OsACO1 is involved in the internode elongation, also, submergence enhances the ACO enzyme activity and levels of OsACO1 mRNA [32, 33]. The expression of OsACO3 and OsACO2 genes in etiolated rice seedlings was also revealed to be diversely controlled via auxin and ethylene [34].

Ethylene is the main hormone, which controls many physiological pathways. Ethylene has been suggested to be more potent versus necrotrophic pathogens (like $B$. cinerea) than against biotrophic pathogens. Ethylene insensitive mutants etr1, ein3, and ein2, display increased susceptibility to $B$. cinerea $[35,36]$. Also, plants that overexpress transcription factors associated with the jasmonic acid and ethylene pathways expose an enhanced resistance to different necrotrophs [37-39]. In Arabidopsis, overexpression of $A P_{2} C_{1}$ that encodes a Thr or Ser protein type $2 \mathrm{C}$ phosphatase decreased production of ethylene and compromises resistance to the necrotrophic pathogen $B$. cinerea [40]. On the other hand, the ACSs could be adjusted via putative endogenous signal receptors like phytohormones and intracellular accumulation of secondary metabolites, such as calcium [3]. Moreover, usage of ACC or ethylene could enhance plant salinity tolerance, mainly by increasing the expression of reactive oxygen species scavengers [41-43]. The expression of ACO genes from various species is also associated with the ethylene biosynthesis rate, as well as ACS, and the transcript levels of multiple ACO genes are regulated under stress conditions [44, 45]. There are some ethylene response factors (ERFs) gene family, across the environmental stress-responsive genes, the mRNA levels of various ERF are controlled via several molecules produced and hormones in various stress 
conditions [46]. Ethylene plays a biphasic role, inhibiting and stimulating growth dependent upon the species, developmental stages of organs or tissue, and environmental conditions [47, 48]. Ethylene prevents hypocotyl elongation by the switch on the transcription factors ethylene response factor 1 (ERF1) [49-51] and waved-dampened 5 (WDL5) in Arabidopsis [52] in the low light severity or dark. Transcription factor hypocotyl 5 (HY5) also gets involved in this action that is degraded via the E3 ligase constitutive photomorphogenic 1 (COP1) [53]. Adjustment of the ACS transcript levels seems to be a critical mechanism to control the alteration of plant ethylene production. Nonetheless, recent studies put forward that posttranslational modifications, like ubiquitination and phosphorylation, provide as a momentous mechanism to adjust the stability of the ACS proteins that will be led to regulate the levels of ethylene in plants $[24,54,55]$.

Considering the riches of the genome sequence information of rice and Arabidopsis which is supplying a valuable resource to study and dissect ethylene biosynthesis genes in monocotyledons (rice) and dicotyledons (Arabidopsis). The genes that are responsible for the biosynthesis of ethylene in Arabidopsis and rice were retrieved delicately. Regarding the importance of the post transcription and translation modifications, the study of the phosphorylation, glycosylation, and miRNA target ethylene biosynthesis genes will be useful. Besides, the cis-regulatory elements in promoter regions of ethylene biosynthesis genes will give a better understanding of the regulation of these genes expression. Moreover, the perception of cis-acting regulatory elements can help to change gene expression patterns through plant genetic engineering approaches to avoid biotic and abiotic stress damages. The present study was the first study to provide comprehensive information and a wide analysis of ethylene biosynthesis genes by available bioinformatics tools for dissection of promoter regions, mRNA, and protein sequences of ethylene biosynthesis genes of two important model plants including Arabidopsis and rice.

\section{Methods}

\section{Retrieve the ethylene genes and sequence analysis}

The involved genes identification for the pathway of ethylene biosynthesis in Arabidopsis and rice were performed using the Plantcyc (https://www.plantcyc.org/). The sequences of transcript and polypeptide of all involving genes in ethylene biosynthesis of Arabidopsis thaliana from the Arabidopsis Information Resource (TAIR) (https://www. arabidopsis.org/) and Oryza sativa from Rice Genome Annotation Project Database (http://rice.plantbiology.msu. edu/index.shtml) were retrieved, respectively [56].

\section{Biochemical characteristics}

Prediction of biochemical traits such as molecular weight $(\mathrm{MW})$, isoelectric point (pI), aliphatic index, instability index, and grand average of hydropathy (GRAVY) was done by polypeptide sequences of ethylene biosynthesis genes and ProtParam tool of Expasy database [57] (https://web.expasy.org/protparam/). The subcellular location of proteins was predicted using Plant-mPLoc (https:// www.csbio.sjtu.edu.cn/bioinf/plant-multi) for both Arabidopsis thaliana and Oryza sativa.

\section{Evolutionary analysis}

The full length of the amino acid sequence of all predicted SAM, ACS, and ACO proteins of rice and Arabidopsis were used to align using ClustalX. The phylogenetic tree was constructed using the neighbor-joining method of clustal omega (https://www.ebi.ac.uk/Tools/msa/clustalo/).

\section{D protein structure prediction and domain analysis}

Three-dimensional (3D) protein structure and ligandbinding site of SAM, ACS, and ACO genes were predicted using the homology modeling of SWISS-MODEL [58]. Also, protein sequences of studied genes were analyzed using the MOTIF Search program https://www.genome.jp/ tools/motif/ for finding the conserved motifs and domains.

\section{Gene expression analysis and identification of miRNA targets}

Microarray expression of intended genes in Arabidopsis thaliana and Oryza sativa under biotic and abiotic stresses and hormones treatment were obtained from the Genevistigator database [59]. The Affymetrix rice genome array (2836 samples) and Affymetrix Arabidopsis ATH1 genome array (10615 samples) were selected to study the expression patterns of ethylene biosynthesis genes in rice and Arabidopsis, respectively. The psRNATarget server (http:// plantgrn.noble.org/psRNATarget/) applied to find existing miRNAs of Arabidopsis thaliana and Oryza sativa at 3.5 expectation level by searching all the transcript sequences of desired genes in Arabidopsis and rice [60].

\section{Prediction of putative Cis-elements}

To identify the probable cis-regulatory elements, the promoter sequences (1500 bp upstream of transcription start site) of ethylene biosynthesis pathway genes in Arabidopsis and rice were perused by plantpan 2 database (http://plantpan2.itps.ncku.edu.tw/index.html) [61].

\section{Prediction the glycosylation and phosphorylation sites}

The NetNGlyc 1.0 server (http://www.cbs.dtu.dk/services/NetNGlyc/) was utilized to determine potential Nglycosylation sites [62]. The predictable phosphorylation sites were identified by NetPhos 3.1 server (http://www. cbs.dtu.dk/services/NetPhos/) [63]. 


\section{Results}

Biochemical characteristics SAM, ACS, and ACO genes in Arabidopsis thaliana and Oryza sativa

The genes which are involved in the pathway of biosynthesis of ethylene in Arabidopsis and rice were detected by the Plantcyc database. According to the ethylene biosynthesis pathway, 26 and 28 engaging enzymes were predicted in $A$. thaliana and O. sativa, respectively (Fig. 1). Besides, from 26 identified genes 4, 9, and 13 were identified as methionine adenosyltransferase (SAM), aminocyclopropane-1carboxylate synthase (ACS), and aminocyclopropane-1carboxylate oxidase (ACO), respectively in A. thaliana, as well as, number of 6, 6, and 16 predicted genes were involved in SAM, ACS, and ACO, respectively, in O. sativa. The number of ACO engaged genes was more than the genes which were involved in SAM and ACS (Fig. 1, Table 1).

The total number of amino acids in studied genes ranged from $251-490$ aa that $A T 3 G 46500$ was the smallest protein involved in ACO and AT4G37770 was the largest predicted protein at ACS in Arabidopsis (Table 1). Also, the length of amino acids varied from 157 to 544 aa in rice that $L O C_{-}$ Os05g05670 was the smallest protein, and LOC_Os10g37899 was the largest protein both engaged with ACO. Furthermore, the high length of proteins was contributed to the ACS in both Arabidopsis and rice (Table 1). The GRAVY values of $A$. thaliana were varied between -0.152 (AT3G50210) a - 0574 (AT2G19590), besides, the GRAVY range was from -0.077 to 0.036 in O. sativa (Table 1).
Molecular weight (MW) of proteins in A. thaliana varied between 27.75 and $55.53 \mathrm{kDa}$ while in $O$. sativa, they ranged between 17.53 and $59.48 \mathrm{kDa}$. Isoelectric points (pI) of proteins in $A$. thaliana ranged from 5.16 (AT3G50210) to 8.5 (AT2G22810) while in O. sativa, they varied from 4.77 (LOC_Os07g29440) to 11.18 (LOC_Os05g35000). Most of the predicted proteins in $A$. thaliana were stable except the proteins involved in ACS; however, in rice, the larger part of the proteins that contribute to the ACS and ACO was unstable (Table 1). The range of the aliphatic index was from 74.55 (AT1G62380) to 89.75 (AT1G35190) in A. thaliana, further, the aliphatic index was varied in $O$. sativa between 70.45 (LOC_Os05g35000) and 96.53 (LOC_ Os02g57990). The lowest and highest aliphatic indices presented in ACO and SAM rice predicted proteins, respectively (Table 1 ). The predicted localization of the proteins was diverse and included the chloroplast, Golgi apparatus, cytoplasm, and nucleus (Table 1). The majority of SAM proteins were localized to the chloroplast in both A. thaliana and O. sativa except LOC_OsO2g57990 (Golgi apparatus), LOC_Os07g29440, and LOC_Os01g10940 (cytoplasm) in $O$. sativa (Table 1). The ACS predicted proteins were localized in the chloroplast and cytoplasm. Besides, most of the ACO proteins were associated with the cytoplasm in both $A$. thaliana and $O$. sativa; however, the LOC_ Os10g37899 and LOC_Os08g33020 were located in the chloroplast as well as cytoplasm and nucleus, respectively (Table 1). The results revealed that genes involved in

\section{L-methionine}

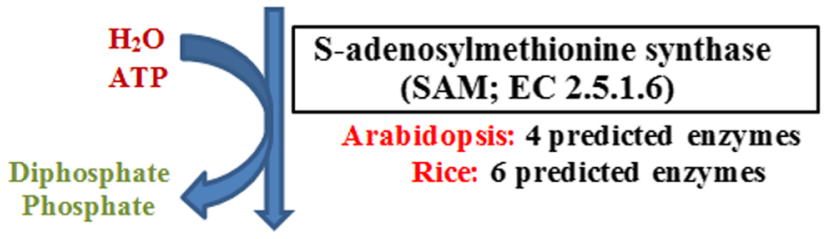

\section{S-adenosylmethionine (AdoMet)}

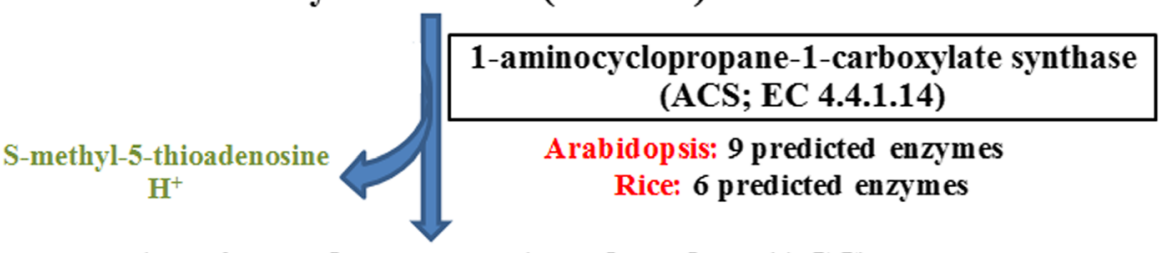

1-aminocyclopropane-1-carboxylate (ACC)

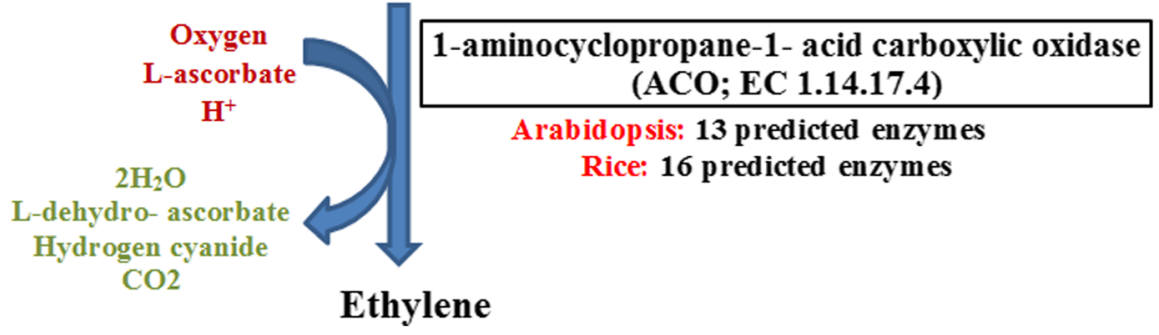

Fig. 1 Ethylene biosynthesis pathway in plant $[11,13]$ 
Table 1 The properties of ethylene biosynthesis genes in Arabidopsis thaliana and Oryza sativa

\begin{tabular}{|c|c|c|c|c|c|c|c|c|}
\hline Locus ID & Gene name & Length (aa) & MW (kDa) & $\mathrm{pl}$ & Instability index & Aliphatic index & GRAVY & Subcellular localization \\
\hline AT2G36880 & SAM3 & 390 & 42.50 & 5.76 & Stable & 86.26 & -0.209 & Chloroplast \\
\hline AT4G01850 & SAM2 & 393 & 43.26 & 5.67 & Stable & 83.74 & -0.236 & Chloroplast \\
\hline AT3G17390 & SAM4 & 393 & 42.80 & 5.51 & Stable & 79.34 & -0.353 & Chloroplast \\
\hline AT1G02500 & SAM1 & 393 & 43.16 & 5.51 & Stable & 85.04 & -0.255 & Chloroplast \\
\hline LOC_Os01g22010 & SAM & 394 & 42.90 & 5.68 & Stable & 81.14 & -0.264 & Chloroplast \\
\hline LOC_Os01g18860 & SAM & 396 & 43.31 & 5.22 & Stable & 82.7 & -0.274 & Chloroplast \\
\hline LOC_Os05g04510 & SAM & 396 & 43.22 & 5.74 & Stable & 82.45 & -0.289 & Chloroplast \\
\hline LOC_Os02g57990 & SAM & 317 & 34.27 & 5.98 & Stable & 96.53 & 0.036 & Golgi apparatus \\
\hline LOC_Os07g29440 & SAM & 164 & 17.80 & 4.77 & Unstable & 75.49 & -0.268 & Cytoplasm \\
\hline LOC_Os01g10940 & SAM & 164 & 17.85 & 4.78 & Stable & 75.49 & -0.291 & Cytoplasm \\
\hline AT3G61510 & ACS1 & 488 & 55.00 & 7.18 & Unstable & 80.33 & -0.306 & Chloroplast \\
\hline AT1G01480 & ACS2 & 496 & 55.53 & 7.2 & Stable & 83.52 & -0.205 & Chloroplast \\
\hline AT2G22810 & ACS4 & 474 & 53.80 & 8.5 & Stable & 87.46 & -0.201 & Cytoplasm \\
\hline AT5G65800 & ACS5 & 470 & 53.31 & 7.55 & Unstable & 83.71 & -0.351 & Cytoplasm \\
\hline AT4G37770 & ACS8 & 496 & 53.37 & 8 & Stable & 81.72 & -0.339 & Cytoplasm \\
\hline AT4G26200 & ACS7 & 447 & 50.67 & 5.94 & Unstable & 82.75 & -0.386 & Chloroplast \\
\hline AT4G11280 & ACS6 & 495 & 55.52 & 6.23 & Unstable & 83.31 & -0.337 & Chloroplast \\
\hline AT4G08040 & ACS11 & 460 & 51.80 & 6.34 & Stable & 80.77 & -0.271 & Cytoplasm \\
\hline AT3G49700 & ACS9 & 470 & 53.17 & 6.73 & Stable & 80.28 & -0.36 & Cytoplasm \\
\hline LOC_Os05g10780 & ACS & 437 & 47.73 & 6.1 & Unstable & 84.92 & -0.111 & Chloroplast \\
\hline LOC_Os01g09700 & ACS & 510 & 55.44 & 7.16 & Unstable & 85.98 & -0.077 & Chloroplast \\
\hline LOC_Os05g25490 & ACS & 496 & 53.51 & 5.66 & Stable & 85.65 & -0.077 & Chloroplast \\
\hline LOC_Os06g03990 & ACS & 542 & 59.48 & 8.99 & Unstable & 87.51 & -0.148 & Chloroplast \\
\hline LOC_Os03g51740 & ACS & 487 & 53.14 & 8.49 & Unstable & 85.17 & -0.115 & Cytoplasm \\
\hline LOC_Os04g48850 & ACS & 483 & 54.34 & 6.83 & Unstable & 80.6 & -0.259 & Chloroplast \\
\hline AT3G46500 & $\mathrm{ACO}$ & 251 & 28.48 & 6.38 & Stable & 85.66 & -0.31 & Cytoplasm \\
\hline AT3G49620 & $\mathrm{ACO}$ & 357 & 40.70 & 6.22 & Stable & 80 & -0.366 & Cytoplasm \\
\hline AT1G35190 & $\mathrm{ACO}$ & 329 & 37.64 & 5.47 & Stable & 89.75 & -0.226 & Cytoplasm \\
\hline AT3G49630 & $\mathrm{ACO}$ & 332 & 37.46 & 5.65 & Stable & 79.12 & -0.409 & Cytoplasm \\
\hline AT4G16765 & $\mathrm{ACO}$ & 247 & 27.75 & 5.33 & Stable & 89.22 & -0.219 & Cytoplasm \\
\hline AT3G50210 & $\mathrm{ACO}$ & 332 & 37.22 & 5.16 & Stable & 89.15 & -0.152 & Cytoplasm \\
\hline AT4G16770 & $\mathrm{ACO}$ & 258 & 29.08 & 5.66 & Unstable & 84.25 & -0.266 & Cytoplasm \\
\hline AT3G46490 & $\mathrm{ACO}$ & 330 & 37.61 & 5.75 & Stable & 78.22 & -0.381 & Cytoplasm \\
\hline AT1G77330 & ACO5 & 307 & 34.95 & 5.05 & Stable & 77.42 & -0.441 & Cytoplasm \\
\hline AT2G19590 & ACO1 & 310 & 35.20 & 6.17 & Stable & 76.84 & -0.574 & Cytoplasm \\
\hline AT1G62380 & $\mathrm{ACO} 2$ & 320 & 36.18 & 4.98 & Stable & 74.55 & -0.487 & Cytoplasm \\
\hline AT1G12010 & $\mathrm{ACO}$ & 320 & 36.53 & 5.09 & Stable & 78.56 & -0.498 & Cytoplasm \\
\hline AT1G05010 & $\mathrm{ACO} 4$ & 323 & 36.68 & 5.24 & Stable & 81.97 & -0.43 & Cytoplasm \\
\hline LOC_Os10g37899 & $\mathrm{ACO}$ & 544 & 59.36 & 6.66 & Unstable & 79.15 & -0.363 & Chloroplast, Cytoplasm \\
\hline LOC_Os04g55070 & $\mathrm{ACO}$ & 326 & 35.80 & 5.34 & Unstable & 83.22 & -0.247 & Cytoplasm \\
\hline LOC_Os05g35000 & $\mathrm{ACO}$ & 222 & 24.68 & 11.18 & Unstable & 70.45 & -0.662 & Chloroplast \\
\hline LOC_Os09g07450 & $\mathrm{ACO}$ & 202 & 22.93 & 5.45 & Stable & 93.66 & -0.311 & Cytoplasm \\
\hline LOC_Os08g33020 & $\mathrm{ACO}$ & 286 & 31.16 & 11 & Unstable & 73.11 & -0.698 & Chloroplast, Nucleus \\
\hline LOC_Os01g61440 & $\mathrm{ACO}$ & 394 & 40.50 & 4.96 & Unstable & 80.61 & -0.09 & Cytoplasm \\
\hline
\end{tabular}


Table 1 The properties of ethylene biosynthesis genes in Arabidopsis thaliana and Oryza sativa (Continued)

\begin{tabular}{lllllllll}
\hline Locus ID & Gene name & Length (aa) & MW $(\mathbf{k D a})$ & $\mathbf{p l}$ & Instability index & Aliphatic index & GRAVY & Subcellular localization \\
\hline LOC_Os09g27820 & ACO & 322 & 36.44 & 4.99 & Unstable & 82.7 & -0.352 & Cytoplasm \\
LOC_Os02g53180 & ACO & 344 & 38.29 & 6.81 & Unstable & 78.63 & -0.368 & Cytoplasm \\
LOC_Os05g05680 & ACO & 308 & 34.58 & 5.11 & Stable & 71.59 & -0.452 & Cytoplasm \\
LOC_Os06g37590 & ACO & 293 & 33.62 & 5.88 & Unstable & 80.82 & -0.423 & Cytoplasm \\
LOC_Os01g39860 & ACO & 312 & 34.03 & 5.21 & Stable & 81.7 & -0.206 & Cytoplasm \\
LOC_Os09g27750 & ACO & 322 & 36.34 & 5.2 & Unstable & 84.25 & -0.315 & Cytoplasm \\
LOC_Os10g37880 & ACO & 308 & 34.24 & 5.35 & Stable & 83.64 & -0.25 & Cytoplasm \\
LOC_Os11g08380 & ACO & 309 & 34.75 & 4.93 & Unstable & 79.61 & -0.403 & Cytoplasm \\
LOC_Os09g07020 & ACO & 435 & 48.94 & 7.1 & Stable & 77.49 & -0.315 & Cytoplasm \\
LOC_Os05g05670 & ACO & 157 & 17.53 & 5.07 & Stable & 73.95 & -0.522 & Cytoplasm \\
\hline
\end{tabular}

ethylene biosynthesis from rice are more varied than these genes from Arabidopsis.

\section{Phylogenetic relationship}

To investigate the evolutionary relationships among involved genes of the ethylene biosynthesis pathway, we constructed the phylogenetic tree by the rooted neighborjoining method using the amino acid sequences from Arabidopsis, and rice (Fig. 2). According to the phylogenic tree, the LOC_Os2g57990 that was predicted to have Golgi apparatus localization had more genetic distance than other rice-SAM genes. Also, two rice-SAM proteins (LOC_Os07g29440 and LOC_Os01g10940) which were predicted to cytoplasm localization had high similarity based on amino acid sequences (Table 1, Fig. 2). According to the evolutionary relationships among SAM proteins, it seems that rice SAM genes had more variation than Arabidopsis SAM genes (Fig. 2). ACS proteins were clustered into three groups that 8 of 15 ACSs were located in the first group. Interestingly, a predicted ACS protein of rice ( $L O C \_O s 06 g 03990$ ) had a high distance with others (Fig. 2). In the first group, AT3G61510, AT1G01480, AT4G11280 (ACS6), and LOC_Os04g8850 had more distance than other ACS proteins from rice and Arabidopsis and it was worth noting that these proteins were predicted to locate in the chloroplast (Table 1, Fig. 2). Also, the evolutionary relationships of ACO proteins revealed that they could be clustered into three groups based on the similarity of amino acid sequences. In this way, the first group contained 15 ACOs while 13 ACOs were clustered into second. The LOC_Os01g61440 had more genetic distance than other the studied ACOs. All Arabidopsis ACO proteins were predicted to have cytoplasm localization, but rice ACO proteins were different in terms of protein localization. Also, phylogenetic analysis between ACO proteins showed that rice ACO proteins had high variation than Arabidopsis ACO proteins (Table 1, Fig. 2).

\section{Protein structure and domain analysis}

In this study, the 3D protein structure of all SAM, ACS, and ACO genes and their ligand-binding site was predicted based on the homology model using the SWISS-MODEL database for predicting the protein-protein interactions (Figs. 3, 4, 5). The ligand-sites for S-adenosylmethionin and protein-ligand interaction profiler (PLIP) were observed in all ArabidopsisSAM proteins and three rice-SAM proteins ( $L O C_{-}$ Os01g18860, LOC_Os01g22010, and LOC_Os0504510) (Fig. 3). The ligand site of MES (2-(N-Morpholino)-ethanesulfonic acid) was observed in all predicted-ACS proteins except AT1G01480 (Fig. 4). Also, the ligand-binding site of PLP (Pyridoxal-5- Phosphate) was found in the structure of ACO proteins. However, the binding sites of AAD ((2-AminooxyEthyl)-[5-(6-Amino-Purin-9-YL)-3, 4-Dihydroxy-Tetrahydro -Furan-2-Ylmethyl]-Methyl-Sulfonium) and 2-Amino-4-(2Amino-Ethoxy)-Butyric acid were observed only in Arabidopsis-ACS proteins (Fig. 5). For most ACO proteins, the ligand-binding site was not predicted; however, the ionbinding sites (Fe, zinc, and nickel ion) were observed in some ACO proteins (Fig. 5). According to the 3D structure and ligand type, AT2G19590 was most similar to LOC Os09g27750 and LOC_Os09g27820, and also, AT3G46500 was similar to LOC_Os10g37899 (Fig. 5).

The motif analysis for SAM, ACS, and ACO proteins was carried out using the MOTIF Search program (https:// www.genome.jp/tools/motif/), separately (Fig. 6). According to the result of motif analysis, location and order of 3 motifs in SAM proteins were similar except for $L O C_{-}$ Os02g57990, LOC_Os07g29440, and LOC_Os01g10940. Moreover, motifs with different lengths and locations observed in LOC_Os02g57990, that the LOC_Os2g57990 was predicted to have Golgi apparatus localization had more genetic distance than other rice-SAM genes (Table 1, Fig. 2, 6). Aminotron_1_2 motif was detected in all of the studied ACS proteins in Arabidopsis and rice, which are almost located in the same position. Besides, Beta_elim_lase was identified in LOC_O05g25490, LOC_Os01g09700, At04g08040, At04g26200, and At01g01480 (Fig. 6). Two 


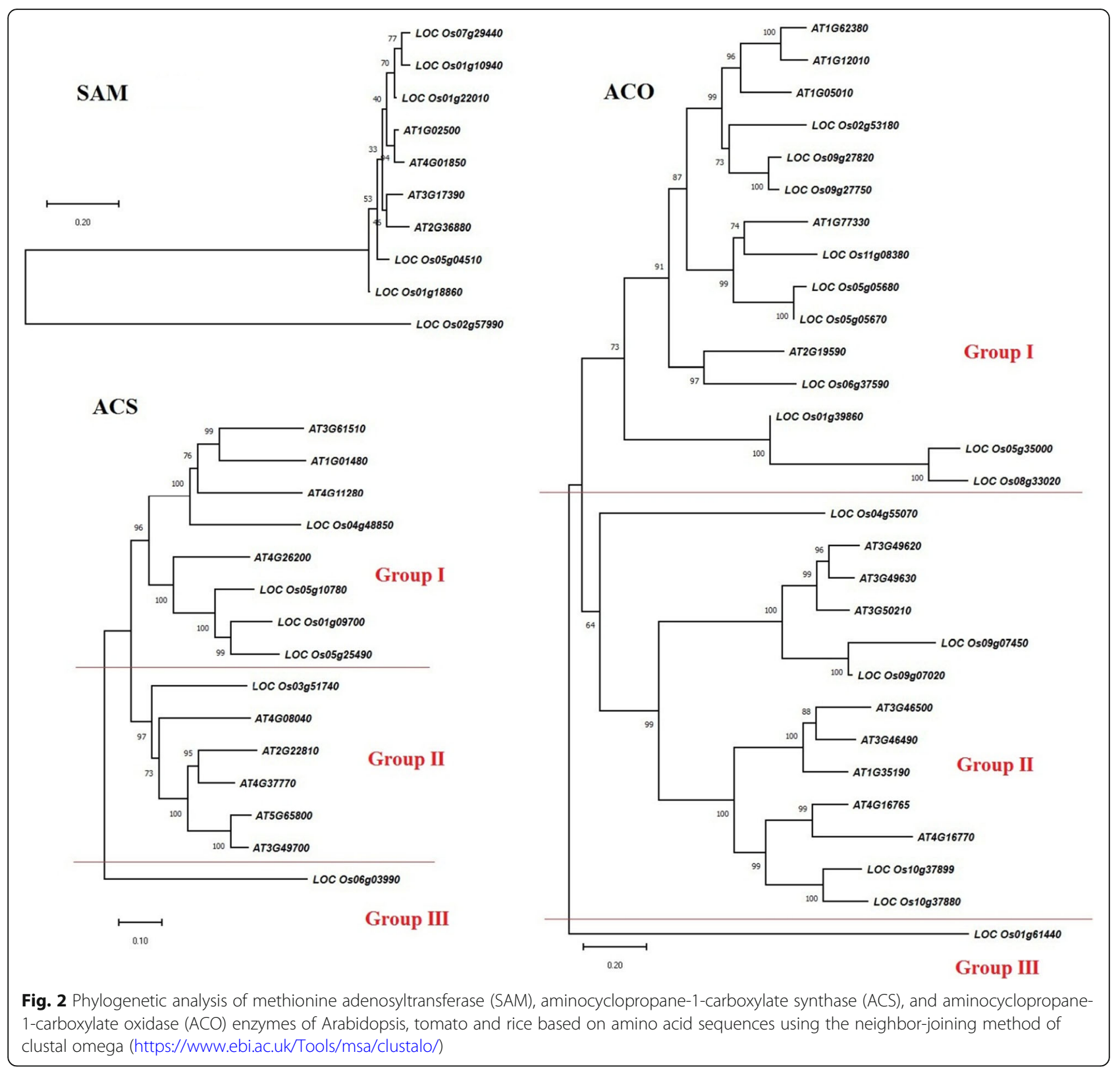

motifs were detected in most of the ACO proteins with identical order in Arabidopsis and rice; however, in some ACO proteins such as At02g19590 and LOC_Os05g05670, proteins had two additional different motifs with various length and locations. The At02g19590 and LOC_ Os05g05670 proteins with 310 aa and 157 aa length, respectively, were predicted as stable proteins and localized in the cytoplasm (Table 1, Fig. 6).

Gene expression: Anatomy, development stages, biotic, and abiotic stresses and hormones treatment

The expression patterns of SAM, ACS, and ACO genes were evaluated in different tissues, organs, growth and development stages, as well as, under biotic and abiotic stresses and hormones treatment in Arabidopsis and rice via microarray data analysis available online using the Genevestigator database (Figs. 7, 8, 9). SAM genes including SAM1, SAM2, METK3, and METK4 high expressed in the primary cell, seedling, inflorescence, shoot and root in Arabidopsis, whereas, LOC_Os01g22010 and LOC_Os05g04510 showed a high level of expression in studied tissue and organs of rice, also, LOC_Os01g18860 and LOC_Os02g57990 expressed in medium level (Fig. 7). In Arabidopsis, ACS1, ACS2, ACS4, ACS5, ACS8, ACS7, ACS6, ACS11, and ACS9 showed exclusive expressions in different tissues and organs. Most of the ACS genes showed medium expressions in studied tissue and organs except ACS5 that expressed in low level in all studied tissues and organs, and ACS6 


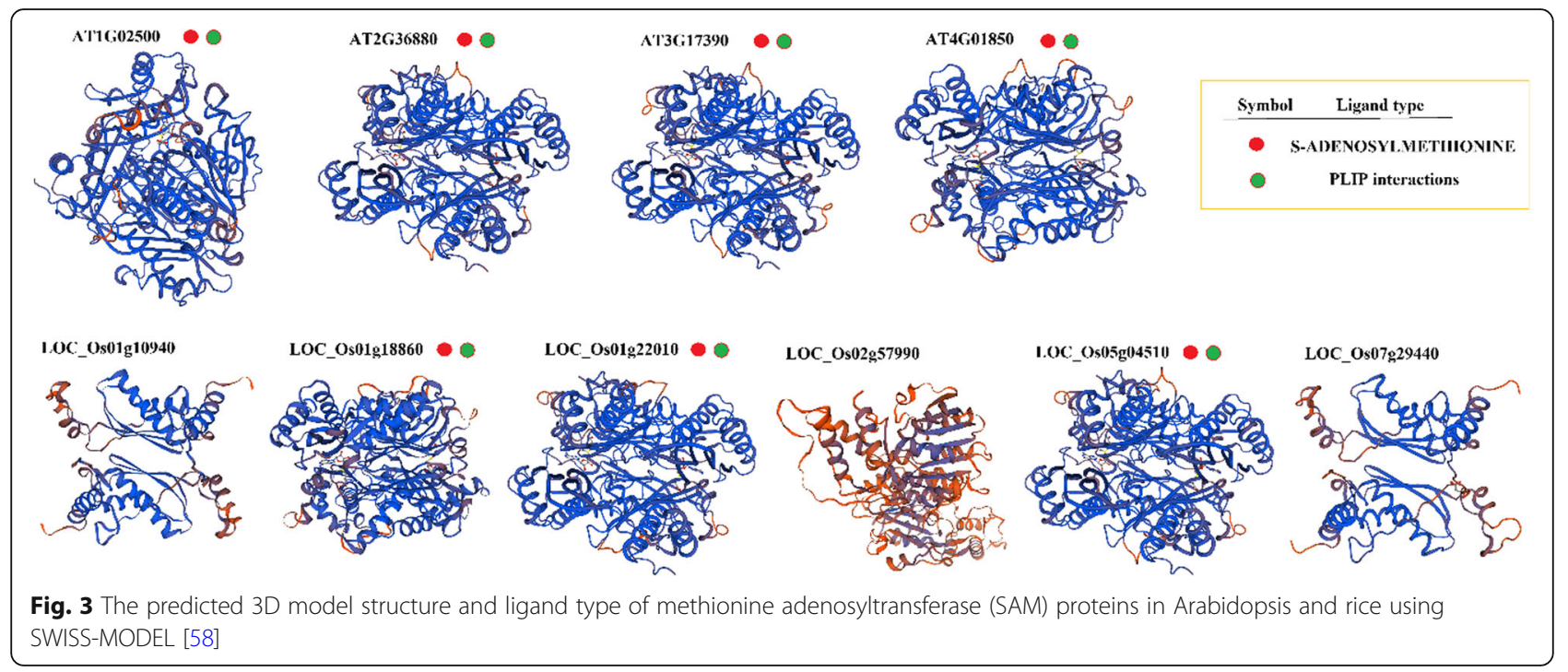

showed a high level of expression in the primary cell, shoot, and root (Fig. 7). In rice, LOC_Os06g03990 displayed a high level of expression in studied tissues and organs, whereas, LOC_Os05g10780, LOC_Os03g51740, LOC_Os04g48850, and LOC_Os01g09700 showed a medium level of expression in all studied tissues and organs except $L O C_{-}$ Os01g09700 had a low level of expression in the inflorescence (Fig. 7). Most of the ACO genes expressed in medium level, DIN11 and At03g46500 showed the lowest level of expression in inflorescence, as well as, At3g46500 had a low expression level in shoot among the studied ACO genes in Arabidopsis. Besides, At01g77330, ACO1, At03g50210, and At01g35190 expressed at a high level at the shoot, also At01g77330 had a high level of expression in the primary cell and seedling. Moreover, At03g50210 demonstrated a high level of expression in the primary cell and inflorescence (Fig. 7). Nine studied ACO showed various expression levels in rice, according to the obtained results LOC_Os10g37899, and LOC_OsO2g53180 revealed the highest level of expression, whereas, LOC_O04g55070

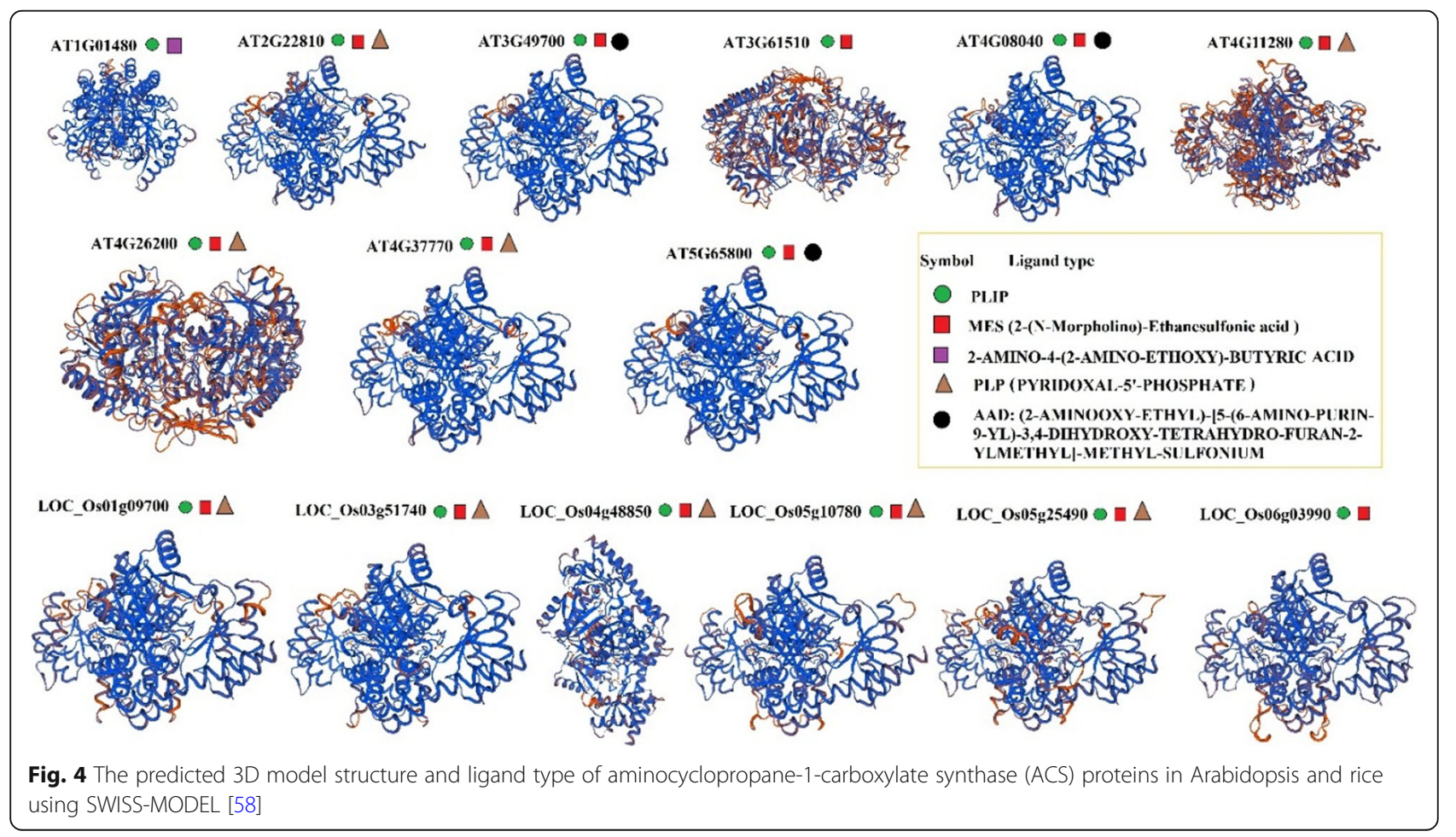




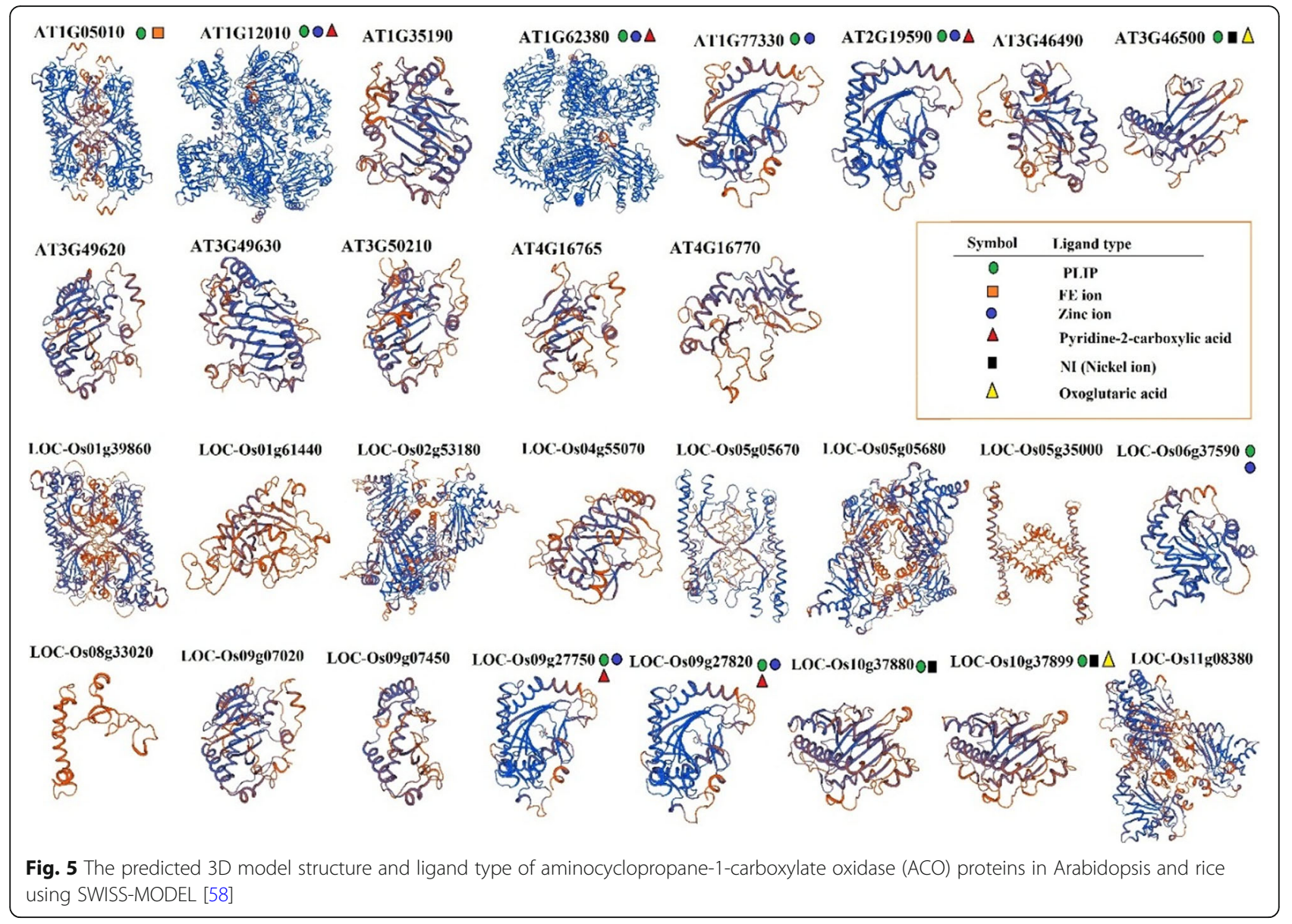

and LOC_O05g35000 showed low expression levels in studied tissue and organs of rice (Fig. 7). It could be concluded that almost all SAM, ACS, and ACO expressed in studied tissue and organs, but at different levels. The results of SAM, ACS, and ACO genes expression were investigated in different growth and development stages (Fig. 8). The Arabidopsis-SAM genes are mostly expressed in the germination stage, while two rice-SAM genes ( $L O C_{-}$ Os01g18860 and LOC_Os01g22010) are highly expressed in the ripening stage. Furthermore, Arabidopsis-ACS2 more induced than other ACS genes that showed high expression in the seeds (Fig. 8). Among ACO genes, At01g35190, and At03g50210 were more up-regulated than others and they had high expression in the seeds. Regarding the gene expression patterns, SAM genes were more involved in the rice-ripening stage, while in Arabidopsis, ACS and ACO genes were contributed in maturity (Fig. 8).

The expression of SAM, ACS, and ACO genes was studied under biotic and abiotic stresses and hormones treatment in Arabidopsis and rice through the existence of microarray data (Fig. 9). The At02g36880 (SAM gene) showed high differential expression under stress conditions in Arabidopsis. The At02g36880 gene is up-regulated in 24$\mathrm{CBL}+$ glucose (dark) in hormone treatment at the seedling stage, but it down-regulated under heat (seedling), salt (root), and temperature, as well as, G. cichoracearum (biotic stress). In rice, the LOC_Os01g22010 gene up-regulated under drought (leaf) and dehydration, on the contrary, it down-regulated in the drought (tillering) and heat stresses, interestingly LOC_OsO2g57990 displayed vice-versa pattern in studied conditions (Fig. 9). Considering to filtration of ACS genes in Arabidopsis, At04g37770 demonstrated various expressions under different stress conditions, where this gene is up-regulated under IAA (seedling), NAA, NAA + FLG22, RALF and shift NPA to NAA, while it downregulated in some abiotic stresses. Besides, the gene expression profile of some ACS genes illustrated that $L O C_{-}$ Os01g09700 gene is especially up-regulated at the different time courses of trans-zeatin treatment and drought stress condition, but it showed down-regulation under heat stress (Fig. 9). Regarding the expression pattern of ACO genes in Arabidopsis, the AT03g49620 and At01g62380 genes showed up-regulation and down-regulation in most of the studied conditions, respectively. While, LOC_OsO1g61440 up-regulated under abiotic stresses consisting of the cold, dehydration, drought, and heat condition in rice (Fig. 9).

It is worth noting that some of the studied genes with similar expression patterns under particular stress had a 


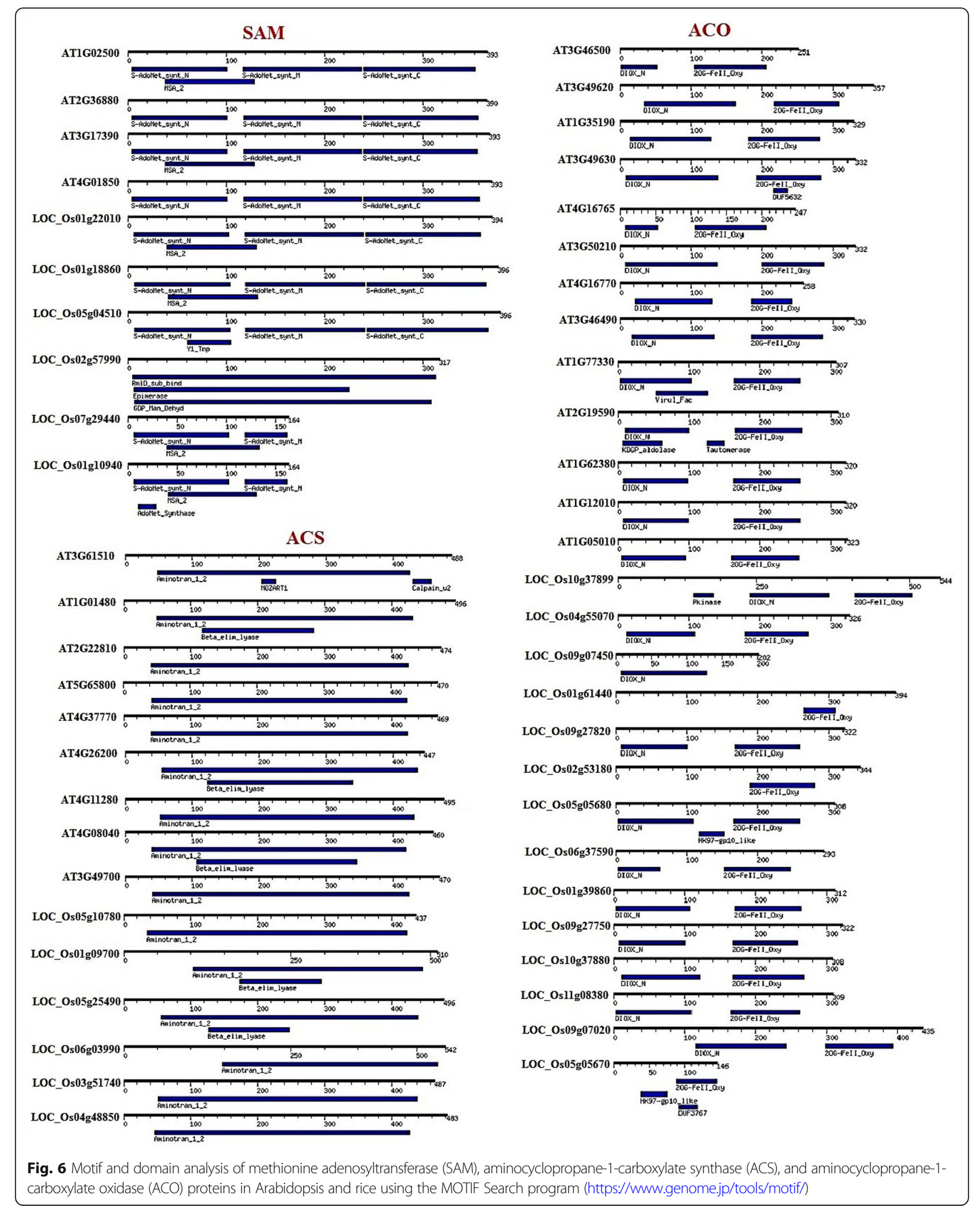




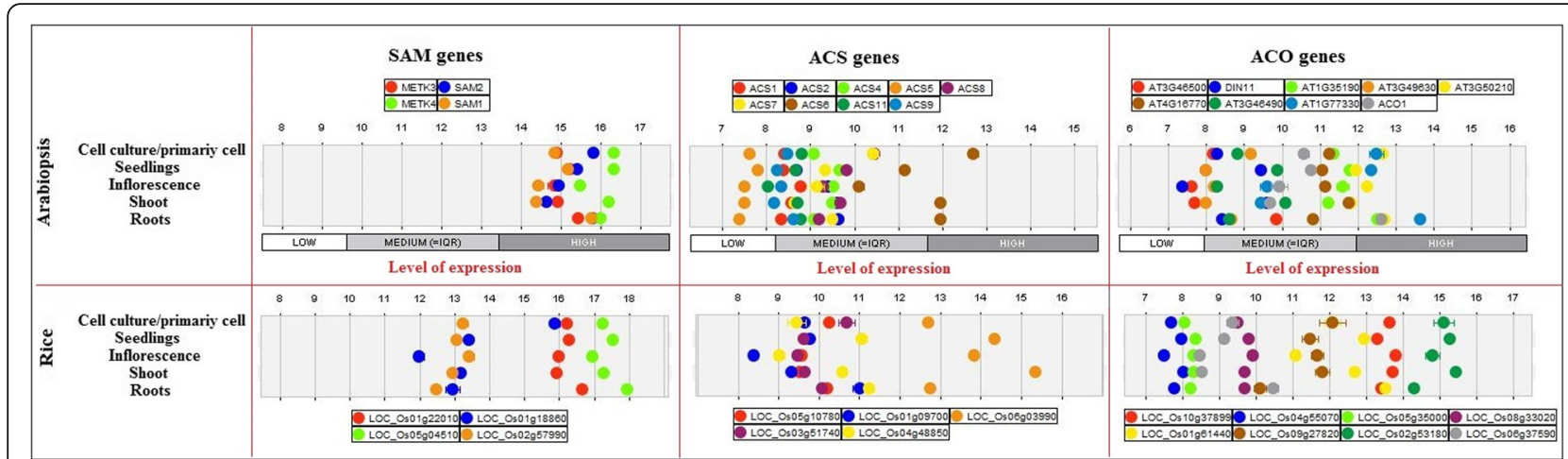

Fig. 7 Expression level of ethylene biosynthesis genes in various tissues and organs of rice and Arabidopsis. The expression data were obtained from Affymetrix Arabidopsis ATH1 genome array using the Genevistigator database [59]

more close evolutionary relationship with each other and were categorized in the same groups. For instance, some ACS genes including At04g37770, At04g26200, and At04g11280 genes are up-regulated under salt stress (late, root) which belonged to group I in phylogeny analysis, also LOC_Os01g09700 and LOC_Os04g48850 showed a high level of expression under drought conditions that categorized in group II (Figs. 2, 9). Moreover, among ACO genes At01g62380 and Ato1g12010 down-regulated under temperature $\left(28^{\circ} \mathrm{C}\right.$ to $\left.19^{\circ} \mathrm{C}\right)$, and $L O C_{-} O s 09 g 27820, L O C_{-}$ Os02g531810 and LOC_Os09g27750 down-regulated under cold stress $\left(4{ }^{\circ} \mathrm{C}\right.$ for $\left.48 \mathrm{~h}\right)$ that clustered in group III regarded to phylogeny analysis (Figs. 2, 9). It seems that similar expression patterns of these genes in exclusive stresses were associated with the alike cis-elements underlying the promoter region of these genes. It reveals that the transcript of these genes adjusted with the identified transcription factors in the same conditions. Thus, gene expression study under various conditions showed environmental signals and stresses influence on the regulation of ethylene biosynthesis pathway, the achieved results could help to figure out how the underlying pathway gene networks were organized and adjusted in various tissues, organs, developmental stages, and stress conditions.

\section{Prediction the miRNA targets}

In the present study, the sites of microRNAs (miRNA) were predicted using published miRNA sequences of

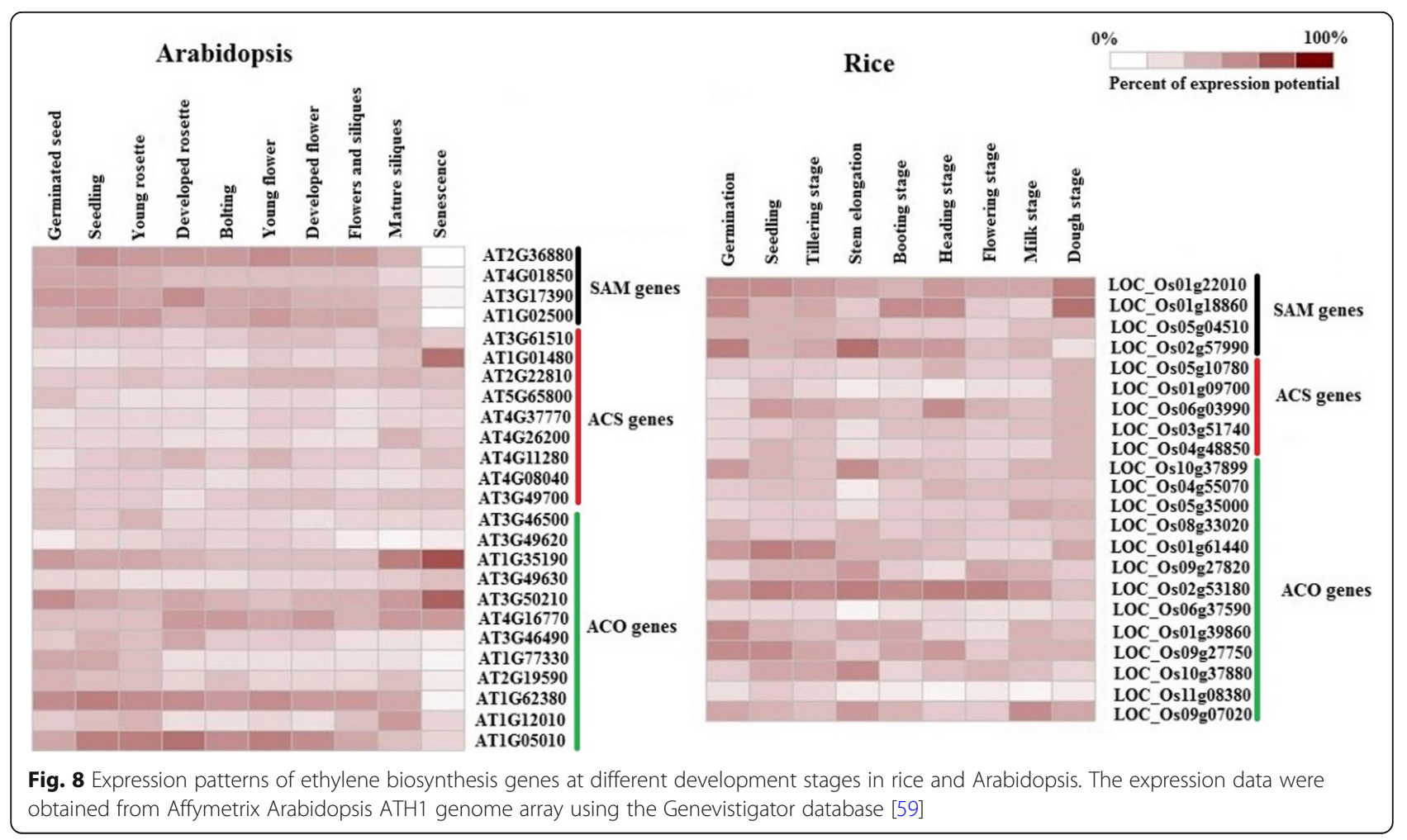




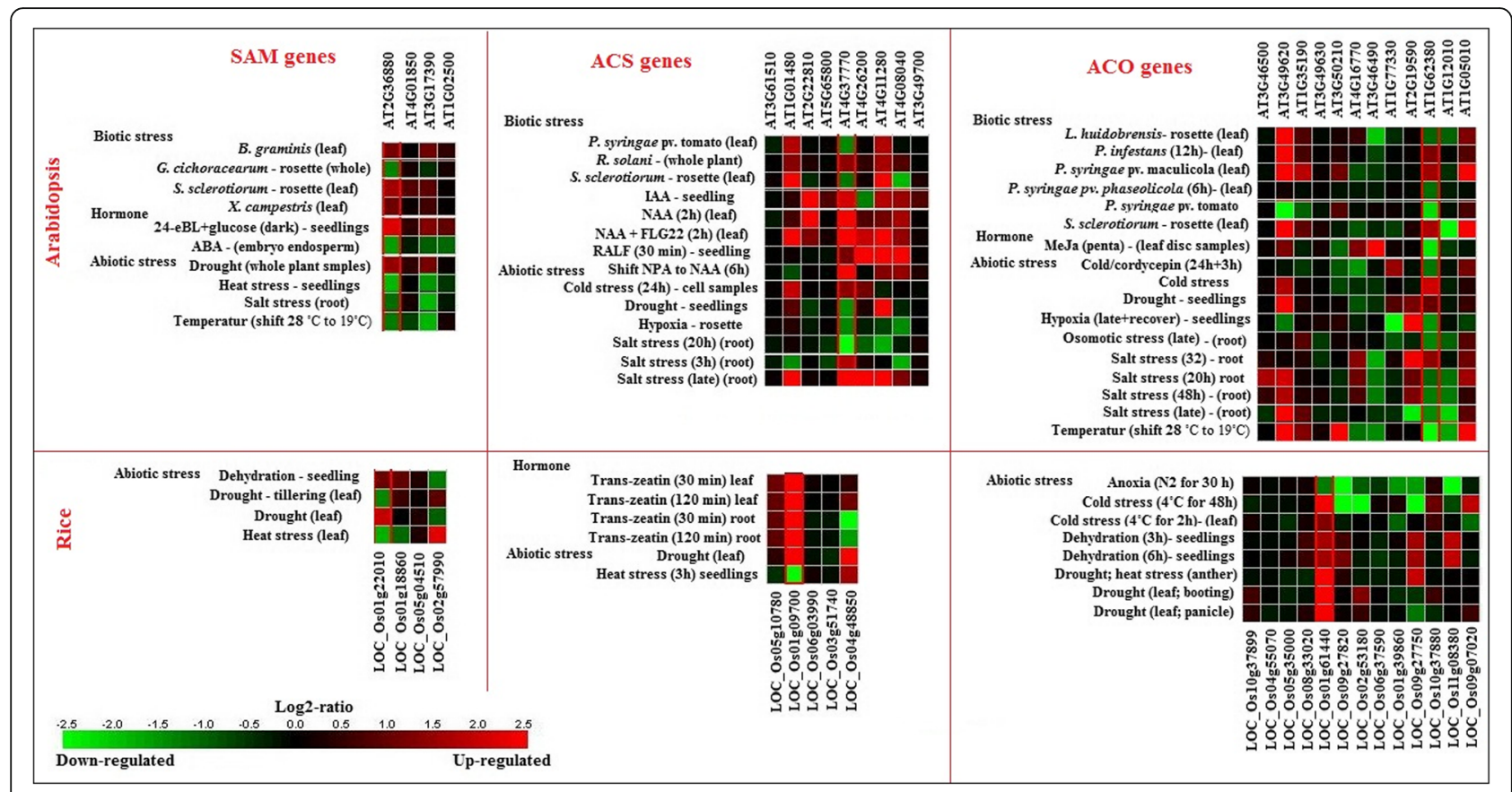

Fig. 9 Differential expression of ethylene biosynthesis genes in rice and Arabidobsis under different biotic and abiotic stresses and hormones treatment. The expression data were obtained from Affymetrix Arabidopsis ATH1 genome array using the Genevistigator database [59]

psRNATarget server for Arabidopsis and rice (Table 2). The result of miRNA targeting the transcript sequences of SAM, ACS, and ACO genes revealed that SAM1 (AT1G02500) from Arabidopsis was targeted by athmiR843 while osa-miR1858 targeted two rice-SAMs (LOC-Os01g22010 and LOC-Os05g04510) transcripts. Two rice-ACOs and one Arabidopsis-ACO contained the link-sites of ath-miR3933, osa-miR5809, and osa-miR531, respectively. All microRNAs inhibition involved the transcript cleavage. In our study, the complex between published miRNAs with transcript sequences of ethylene biosynthesis genes in $A$. thaliana and $O$. sativa were identified that would be helpful to understand the regulation the gene expression after the transcription process.

\section{Cis-regulatory elements in promoter site}

Gene expression is broadly adjusted in the transcription phase, where the interactions amongst cis-regulatory elements and transcription factors in the promoter region of the genes which perform a crucial role. In other words, the cis-regulatory elements (CREs) as non-coding DNA are mainly located in upstream of genes, which are determined via transcription factors that control the gene expression in various conditions. Analyses of the promoter region of the induced genes led to the discovering of cis-acting elements, also the ethylene-responsive element-binding protein (EREBP) family that interacts with ethylene response factors (ERFs) and DNA [3]. Transcription factors related to the ERF family have

Table 2 Putative miRNAs targeted the transcripts of ethylene biosynthesis genes

\begin{tabular}{|c|c|c|c|c|c|}
\hline miRNA ID & Target ID & miRNA sequence (3-5) & Target position & Expectation & Inhibition \\
\hline ath-miR843 & AT1G02500 (SAM1) & AGGUUACUUCGAGCUGGAUUU & $1333-1353$ & 3 & Cleavage \\
\hline ath-miR843 & AT2G22810 (ACS4) & AGGUUACUUCGAGCUGGAUUU & $675-694$ & 2.5 & Cleavage \\
\hline ath-miR159a & AT2G22810 (ACS4) & AUCUCGAGGGAAGUUAGGUUU & $437-457$ & 3 & Cleavage \\
\hline ath-miR159a & AT4G37770 (ACS8) & UCCUCGAGGGAAGUUAGGUUU & $458-478$ & 1.5 & Cleavage \\
\hline ath-miR3933 & AT1G77330 (ACO5) & GGCUCAGCAGUAAAACGAAGA & 739-759 & 2.5 & Cleavage \\
\hline osa-miR1858 & LOC_Os01g22010 (SAM) & CGGGGUGAGGCAGGAGGAGAG & $567-587$ & 3 & Cleavage \\
\hline osa-miR1858 & LOC_Os05g04510 (SAM) & CGGGGUGAGGCAGGAGGAGAG & $570-590$ & 3 & Cleavage \\
\hline osa-miR5809 & LOC_Os05g05680 (ACO) & CGACACCAGCGGCCGCUGCU & $802-821$ & 3 & Cleavage \\
\hline osa-miR531a & LOC_Os11g08380 (ACO) & UACCGCCGUGCGUCGGGGCCGCUC & $900-923$ & 3 & Cleavage \\
\hline osa-miR531b & LOC_Os11g08380 (ACO) & GCCGUGCGUCGGGGCCGCUC & 904-923 & 3 & Cleavage \\
\hline
\end{tabular}


been demonstrated to be engaged in several developmental processes [64-66], abiotic [67, 68], and biotic [69] stress responses. The upstream of studied genes (promoter site) was screened to identify the key cis-elements that regulate the gene expression under different conditions (Table 3). The AAACAAA sequence named anaero1 consensus was observed in the most promoter sites of ethylene biosynthesis genes of $A$. thaliana and $O$. sativa. The anaero1 consensus is one of the motifs found in the promoters of anaerobic genes involved in the fermentative pathway [76]. The binding sites of common transcription factors such as MYB, WRKY, and ABRE that control target genes in abiotic and biotic stresses were generally distributed in promoter sites of ethylene biosynthesis genes of $A$. thaliana. SORLIP1AT, SURECOREATSULTR11, ABRELATERD1, MYBCOREATCYCB1, and LS7ATPR1, discovered in promoter site of all the ethylene biosynthesis genes of A. thaliana genes that these cis-motifs are engaged to response light-induced cotyledon and root genes [70], sulfurresponsive element [71], dehydration [72], cell cycle phaseindependent activation and salicylic acid [73], respectively. Besides, the binding sites of some key cis-regulatory elements such as BIHD1OS, CGACGOSAMY3 and GARE2OSREP1 that involved in disease resistance [78], sugar starvation [79] and gibberellin-responsive element (GARE) [81], respectively, were commonly distributed in promoter sites of ethylene biosynthesis genes of O. sativa.

\section{Potential phosphorylation and glycosylation sites}

Phosphorylation and glycosylation are the prevalent posttranslational modification of proteins which could modify object site and activity of protein [82]. The potential phosphorylation sites of studied proteins were predicted based on the presence of serine, threonine, and tyrosine amino acids (Fig. 10). Phosphorylation is catalyzed by kinases that transmit a phosphoryl group commonly from ATP, but also from ADP to the hydroxyl group of particular Ser, Tyr, or Thr residues in their target proteins. Nevertheless, also His and both Asp and His in plant twocomponent signaling can be phosphorylated [83-86]. The result illustrated that the LOC_Os05g05670 (as an ACO protein) had the minimum phosphorylation sites while the highest phosphorylation number (53 sites) predicted in LOC_Os06g03990 (as an ACS protein). The predicted phosphorylation sites in SAM, ACS and ACO proteins of Arabidopsis ranged from 19 (AT3G49630 as an ACO protein) to 48 (AT1G01480 as an ACS protein). According to our findings, the ACO proteins were less phosphorylated than ACS and SAM proteins. This is likely that phosphorylation of ACS adjusts ethylene production was supported through the study that mutation of the C-terminal extension of ACS5 in Arabidopsis persuades the eto2-1 mutant to overproduce. The predicted-glycosylation sites within amino acid sequences of SAM, ACS, and ACO proteins were presented in table 4. All Arabidopsis-SAMs showed similar glycosylation patterns while the glycosylation patterns were very different in rice-SAMs and $50 \%$ of them were not predicted any glycosylation site. ACS proteins showed the highest glycosylation sites whereas AT2G22810 (ACS4) had four predicted-glycosylation sites (as hyperglycosylated protein). The rice-ACO proteins showed the minimum predicted-glycosylation sites that $75 \%$ had no glycosylation site. Also, $38 \%$ of ArabidopsisACO proteins had no potential glycosylation site.

Table 3 List of key cis-regulatory elements of promoter site of ethylene biosynthesis genes

\begin{tabular}{|c|c|c|c|c|}
\hline \multirow[t]{2}{*}{ Identifier } & \multirow[t]{2}{*}{ Sequence } & \multicolumn{2}{|l|}{ Cover $\%$} & \multirow[t]{2}{*}{ Annotation } \\
\hline & & Arabidopsis & Rice & \\
\hline SORLIP1AT & GCCAC & 100 & - & $\begin{array}{l}\text { Over-represented in light-induced cotyledon and root common genes } \\
\text { and root-specific genes [70] }\end{array}$ \\
\hline SURECOREATSULTR11 & GAGAC & 100 & - & Sulfur-responsive element [71] \\
\hline ABRELATERD1 & ACGTG & 100 & - & Responsive to dehydration [72] \\
\hline MYBCOREATCYCB1 & AACGG & 100 & - & Involved in cell cycle phase-independent activation \\
\hline WBBOXPCWRKY1 & TTGACY & 100 & - & W box; WRKY \\
\hline LS7ATPR1 & ACGTCATAGA & 100 & - & A positive salicylic acid-inducible element [73] \\
\hline XYLAT & ACAAAGAA & 96.2 & - & Involved in secondary xylem development and wood formation [74] \\
\hline CCA1ATLHCB1 & AAMAATCT & 92.3 & - & Involved in the phytochrome regulation [75] \\
\hline ANAERO1CONSENSUS & AAACAAA & 96.2 & 96.2 & Involved in the fermentative pathway [76] \\
\hline SITEIOSPCNA & CCAGGTGG & - & 100 & Resemble G-box; May contribute in part to transcriptional activation [77] \\
\hline BIHD1OS & TGTCA & - & 100 & Involved in disease resistance [78] \\
\hline CGACGOSAMY3 & CGACG & - & 100 & Involved in sugar starvation [79] \\
\hline E2F1OSPCNA & GCGGGAAA & - & 100 & Involved in actively dividing cells and tissue [80] \\
\hline GARE2OSREP1 & TAACGTA & - & 100 & Gibberellin-responsive element (GARE) [81] \\
\hline
\end{tabular}



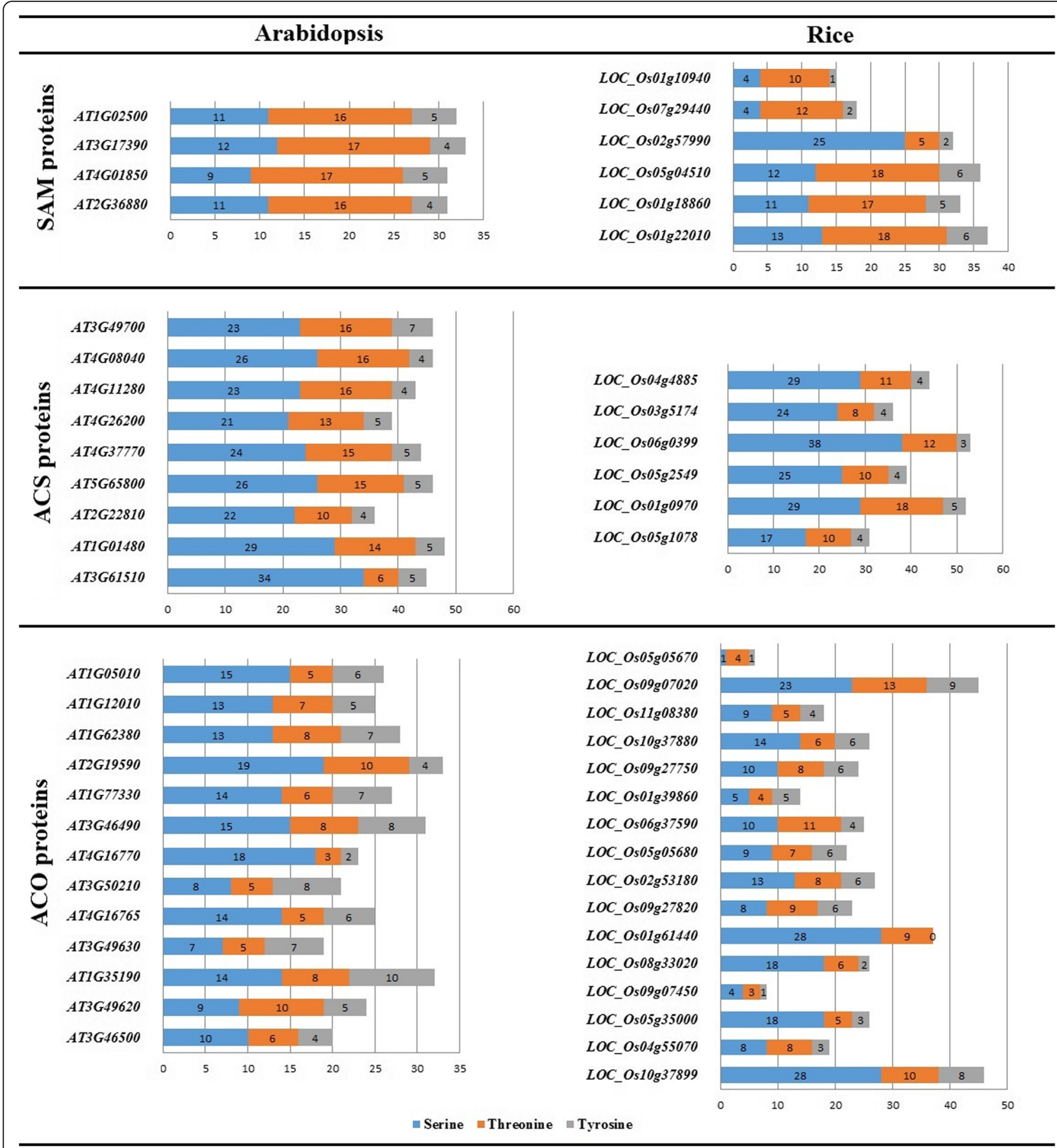

Fig. 10 The predicted sites of phosphorylation in amino sequences of methionine adenosyltransferase (SAM), aminocyclopropane-1-carboxylate synthase (ACS), and aminocyclopropane-1-carboxylate oxidase (ACO) proteins in Arabidopsis and rice using NetPhos 3.1 server (http://www.cbs.dtu.dk/services/NetPhos/) [63]

\section{Discussion}

Ethylene is one of the simplest well-characterized plant hormones and ethylene biosynthesis including three simple steps, beginning from the amino acid methionine in both dicot and monocot plants [13]. Firstly, methionine is transformed to S-adenosyl methionine (SAM), which is afterward converted to 1-aminocyclopropane-1-carboxylic acid (ACC) via $\mathrm{ACC}$ synthases (ACS). Eventually, ACC is converted to ethylene through ACC oxidases (ACO) [87]. In this study, 26 and 28 engaging genes involving in the ethylene biosynthesis pathway, were predicted in A. thaliana and O. sativa, respectively. The selected SAM, ACS, and ACO genes in 
Table 4 The predicted N-glycosylation sites in amino sequences of methionine adenosyltransferase (SAM), aminocyclopropane-1carboxylate synthase (ACS), and aminocyclopropane-1-carboxylate oxidase (ACO) proteins in Arabidopsis and rice using NetNGlyc 1.0 server (http://www.cbs.dtu.dk/services/NetNGlyc/) [62]

\begin{tabular}{|c|c|c|c|c|}
\hline & \multicolumn{2}{|c|}{ Arabidopsis thaliana } & \multicolumn{2}{|l|}{ Oryza sativa } \\
\hline & Locus ID & Glycosylation site & Locus ID & Glycosylation site \\
\hline \multirow[t]{6}{*}{ SAM proteins } & AT2G36880 & $2(158,233)$ & LOC_Os01g22010 & $2(160,235)$ \\
\hline & AT4G01850 & $2(158,233)$ & LOC_Os01g18860 & $1(236)$ \\
\hline & AT3G17390 & $2(158,233)$ & LOC_Os05g04510 & $2(161,236)$ \\
\hline & AT1G02500 & $2(158,233)$ & LOC_Os02g57990 & 0 \\
\hline & & & LOC_Os07g29440 & 0 \\
\hline & & & LOC_Os01g10940 & 0 \\
\hline \multirow[t]{9}{*}{ ACS proteins } & AT3G61510 & $1(131)$ & LOC_Os05g10780 & $1(189)$ \\
\hline & AT1G01480 & $2(132,207)$ & LOC_Os01g09700 & $2(264,496)$ \\
\hline & AT2G22810 & $4(124,199,447,456)$ & LOC_Os05g25490 & $1(217)$ \\
\hline & AT5G65800 & $2(124,199)$ & LOC_Os06g03990 & $2(140,282)$ \\
\hline & AT4G37770 & $2(124,199)$ & LOC_Os03g51740 & $2(46,211)$ \\
\hline & AT4G26200 & $2(50,214)$ & LOC_Os04g48850 & $2(21,204)$ \\
\hline & AT4G11280 & $3(27,210,229)$ & & \\
\hline & AT4G08040 & $3(34,122,197)$ & & \\
\hline & AT3G49700 & $2(124,199)$ & & \\
\hline \multirow[t]{16}{*}{ ACO proteins } & AT3G46500 & 0 & LOC_Os10g37899 & 0 \\
\hline & AT3G49620 & $1(124)$ & LOC_Os04g55070 & $1(307)$ \\
\hline & AT1G35190 & $2(3,23)$ & LOC_Os05g35000 & 0 \\
\hline & AT3G49630 & $1(99)$ & LOC_Os09g07450 & $1(98)$ \\
\hline & AT4G16765 & 0 & LOC_Os08g33020 & 0 \\
\hline & AT3G50210 & $1(98)$ & LOC_Os01g61440 & 0 \\
\hline & AT4G16770 & $1(194)$ & LOC_Os09g27820 & 0 \\
\hline & AT3G46490 & $1(3)$ & LOC_Os02g53180 & 0 \\
\hline & AT1G77330 & 0 & LOC_Os05g05680 & 0 \\
\hline & AT2G19590 & $1(110)$ & LOC_Os06g37590 & 0 \\
\hline & AT1G62380 & 0 & LOC_Os01g39860 & 0 \\
\hline & AT1G12010 & 0 & LOC_Os09g27750 & 0 \\
\hline & AT1G05010 & $1(99)$ & LOC_Os10g37880 & $1(178)$ \\
\hline & & & LOC_Os11g08380 & 0 \\
\hline & & & LOC_Os09g07020 & $3(65,70,205)$ \\
\hline & & & LOC_Os05g05670 & 0 \\
\hline
\end{tabular}

Arabidopsis and rice were variable in physicochemical properties including protein length, GRAVY value, aliphatic index, molecular weight, isoelectric points (pI), and instability index. The GRAVY values in involved-ethylene biosynthesis genes of Arabidopsis were more varied than rice. The GRAVY value associated with the solubility of proteins, and it could calculate the sum of hydropathy values $[88,89]$. According to the predicted GRAVY value, ACS enzymes of Arabidopsis are more hydrophilic than ACS enzymes of rice. Besides, the ACOs of rice showed high variation based on physicochemical properties. Besides, the lowest and highest aliphatic indices observed in ACO and SAM rice predicted proteins, respectively. The aliphatic index is an important factor for the thermostability of proteins [90]. Research showed that Arabidopsis 14-3-3 protein exploits as positively adjusting the ethylene biosynthesis via increasing the ACS protein stability by the interaction with ACS proteins [55]. The proteins by high aliphatic index may have a greater half-life and they could be engaged in high reaction temperature [91].

Regarding the appearance and advancement of the genomic era, progressively, more genome sequences are 
released, which pave the way for evolutionary and comprehensive studies of any gene family from various species [82]. Our result based on studied predicted proteins indicated that involved-proteins in the ethylene biosynthesis pathway of rice had high variation than Arabidopsis. Lee and Yoon [20] indicated that the similarity of structure and the conserved regulatory motif discovered in both ACS proteins from these two plant species rice and Arabidopsis indicate the being of an evolutionally conserved mechanism, which underlies the ethylene biosynthesis regulation in rice and Arabidopsis. Also, the different ligand sites were observed in the predicted-3D structure of ACO and ACS proteins. Illuminating the biochemical and biological roles of proteins to determine their interacting partners, could be time-consuming and hardly implement by in vivo and/or in vitro approaches, besides most of the recently sequenced proteins will have unclear functions and structures as well. Although, computational approaches for predicting protein-ligand binding sites suggest an alternating practical solution. Therefore, it is momentous to discover these key sites to understand the protein function [92-94]. MES (2-(N-Morpholino)-ethanesulfonic acid) binding site was observed in all predicted-ACS proteins except AT1G01480, while the binding sites of AAD ((2-Aminooxy-Ethyl)-[5-(6-Amino-Purin-9-YL)-3,4-Dihydroxy-Tetrahydro-Furan-2-Ylmethyl]-Methyl-Sulfonium) and 2-Amino4-(2-Amino-Ethoxy)-Butyric acid just observed in Arabidopsis-ACS proteins. The structure of the ligandbinding site can influence the protein function, protein evolution, and protein-protein interaction [95].

Ethylene plays a main role in the senescence and fruit ripening initiation, also boosts the transcription and translation of responsive genes engaged to fruit softening, cellwall metabolism, and membrane metabolism, via switching on the ethylene signaling transduction $[89,96,97]$. The results of gene expression demonstrated that SAM, ACS, and ACO genes were differentially induced in plant development stages and they had different expression patterns in monocots and dicotyledonous in response to stresses. ACS2 gene of Arabidopsis is more induced than other ACS genes showing high expression in seeds. In Arabidopsis, ACS transcripts have been illustrated in etiolated seedlings, roots, stems, leaves, siliques, and flowers [18, 98, 99]. Each of the multigene family is differentially expressed for the time of auxin treatment, wounding, and ripening [100]. For example, LE-ACS4, and LE-ACS2 genes are expressed at the ripening time in tomato [101], persuaded in mature green fruits after treatment by exogenous ethylene [101, 102] and over induced upon pericarp tissues wounding [103]. Some ACS genes including At04g37770, At04g26200, and At04g11280 genes were up-regulated under salt stress. Lelièvre et al. indicated that expression of the ACC synthase gene is controlled through ethylene only during/ after chilling treatment, but the expression of the ACC oxidase gene could be regulated separately through either ethylene or chilling [104]. As already noted, in Arabidopsis, various abiotic stresses often enhance ethylene biosynthesis by enhancing the transcription of distinct subsets of ACS genes. Transcript levels of the ACS6 gene elevate in response to ozone [105]. ACS2, $A C S 9, A C S 6$, and $A C S 7$ are induced during hypoxia [106], but the expression of all the ACS genes decreased under anaerobic conditions in Arabidopsis [98]. Nevertheless, the transcript levels of separate subsets of the ACS genes enhance in response to osmotic stress, drought, high temperatures conditions, and after wounding $[98,99]$. Gene expression is broadly adjusted in the transcription phase, where the interactions amongst cis-regulatory elements and transcription factors in the promoter region of the genes which perform a crucial role. The binding sites of important transcription factors including ABRE, MYB, and WRKY that regulate target genes under stresses were generally distributed in promoter sites of ethylene biosynthesis genes of $A$. thaliana. Considering the regulatory role of these elements could distinguish much of plant stress response by these elements existence $[46,107,108]$. Also, different cis motifs including sulfur-responsive element, dehydration, and hormone (salicylic acid, gibberellin, and abscisic acid) responsive elements were observed in upstream of SAM, ACO, and ACS genes. Cis-acting elements are particular binding sites for proteins that engaged in the initiation and regulation of transcription, which is suppressing or activating the gene transcription in response to altering growth conditions and different environmental stress [109]. Our results indicated that the most SAM and ACO genes were down-regulated in response to abiotic stresses that various factors such as type of cis-regulatory elements may affect the expression patterns. Collectively, the current study revealed that involved genes in the ethylene biosynthesis pathway play key roles, not only in regulating development stages such as the ripening stage but also in regulating the response to abiotic and biotic stresses tolerance.

The result of miRNA targeting the transcript sequences of SAM, ACS, and ACO genes showed that ath-miR843 and osa-miR1858 play a key role to regulate the posttranscription modification of SAM genes in Arabidopsis and rice, respectively. The ath-miR843 involves in response to low-oxygen (hypoxia) stress [110], and osamiR1858 is one of the mirRNA that is related to rice grains development [111]. Also, the target site of athmiR159a was found in the transcript sequence of AT2G22810 and AT4G37770 as ACS genes. MIR159a is a key microRNA that targets mRNAs coding of MYB proteins that bind to the regulative site of floral meristem identity gene LEAFY [112], also ath-miR159a involved in hypoxia stress [110]. The prediction result of the posttranslation modification showed that ACS proteins were more phosphorylated and glycosylated. Phosphorylation 
and glycosylation are the prevalent post-translational modification of proteins which could modify object site and activity of protein [82]. Phosphorylation, as one of the most plentiful post-translational modifications, plays the main role in plant metabolism and signal transduction via modifying protein interactions, protein activities, or subcellular location [24, 86, 113-115]. Regarding evidence, it seems that the biosynthesis of ethylene is adjusted by phosphorylation events that probably affect the ACS protein turnover. Working on the usage of phosphatase inhibitors and kinase in tomato tissues and suspension cell cultures demonstrated that phosphorylation influence the activity and/or turnover of ACS [116]. Thus, it seems that ACS phosphorylation preserves the protein from the destruction that in turn may lead ACS to accumulate and ACS activity to enhance, considering for the burst of ethylene production via ripening fruit [117], noteworthy, LeACS2 protein of tomato has been discovered to be phosphorylated in response to wounding [117]. The glycosylation could make alterations to the stability of the protein [118] and protein's molecular weight [119]. To sum up, it seems the ethylene biosynthesis proteins from Arabidopsis were more glycosylated than rice's proteins. Some studies highlight the possibility of posttranslational regulation of ACS $[115,118]$.

\section{Conclusion}

Nowadays, computational analysis plays a substantial role in plant science. Appropriate computational approaches coupled with suitable databases are fundamental for detecting, organizing, integrating data information content furnishing novel insights into the involved genes in important pathways and biological systems as well. Ethylene is a gaseous hormone that controls various physiological pathways. In this study, the involved genes in ethylene biosynthesis were evaluated using available bioinformatics tools in Arabidopsis and rice. Results revealed that involved-enzymes in ethylene biosynthesis had more variation based on physic-chemical characters and patterns of gene expression, protein structure, post-translation modification, and type of cis-regulatory elements. The genes in the ethylene biosynthesis pathway of rice had high variation than Arabidopsis indicated that probably SAM, ACS, and ACO genes of dicots such as Arabidopsis are derived from monocot such as rice. All SAM, ACS, and ACO genes are expressed in studied tissue and organs, but at different levels. SAM genes are more involved in the rice-ripening stage, while in Arabidopsis, ACS and ACO genes are contributed in maturity. Also, the SAM, ACS, and ACO genes expression of rice in different tissue and organs demonstrated more variation in comparison with the Arabidopsis genes. Regarding the post-translation modification result, the ACO proteins were less phosphorylated than ACS, and SAM proteins, and it seems the ethylene biosynthesis proteins from
Arabidopsis were more glycosylated than rice's proteins that can affect the protein activity, or subcellular location. Overall, the current study described that involved genes in the ethylene biosynthesis pathway play the key roles in controlling the response to abiotic and biotic stresses tolerance that various factors such as PPIs, type of cisregulatory elements, and post-transcription/translation modifications could affect their expression. Our study was the first in silico and review study which widely assessed SAM, ACS, and ACO genes that are involved in ethylene biosynthesis and it provided an expanded landscape of computational analysis for further dissection and functional characterization of SAM, ACS, and ACO genes.

\section{Abbreviations}

PGRs: Plant growth regulatorsmiRNAMicro-RNASAMSadenosylmethionineACC1-Aminocyclopropane-1-carboxylateACOACC oxidaseCDPKCalcium-dependent protein kinaseMAPKMitogen-activated protein kinaseERFEthylene response factorTFsTranscription factorsCAREsCisacting regulatory elementsMWMolecular weightpllsoelectric pointGRAV YGrand average of hydropathyPPIProtein-protein interaction

\section{Acknowledgements}

Not applicable.

Authors' contributions

$\mathrm{PH}$ designed and managed the work. $\mathrm{MA}, \mathrm{SH}$, and $\mathrm{PH}$ analyzed and wrote the original draft. All authors read and approved the final manuscript.

Funding

Not applicable

Availability of data and materials

The datasets and raw data are available from the corresponding author on reasonable request.

Ethics approval and consent to participate

Not applicable.

Consent for publication

Not applicable

Competing interests

The authors declare that they have no competing interests.

\section{Author details}

'Minab Higher Education Center, University of Hormozgan, Bandar Abbas, Iran. ${ }^{2}$ Department of Life Sciences, National University of Kaohsiung, Kaohsiung 811, Taiwan. ${ }^{3}$ Department of Horticultural Sciences, Faculty of Agriculture, Shahrood University of Technology, Shahrood, Iran. ${ }^{4}$ National Key Laboratory of Crop Genetic Improvement, College of Plant Science and Technology, Huazhong Agricultural University, Wuhan 430070, Hubei, China. ${ }^{5}$ Department of Agronomy and Plant Breeding, Faculty of Agriculture, Shahrood University of Technology, Shahrood, Iran.

Received: 20 January 2020 Accepted: 2 October 2020

Published online: 19 October 2020

\section{References}

1. Argueso CT, Hansen M, Kieber JJ (2007) Regulation of ethylene biosynthesis. J Plant Growth Regul 26:92-105 https://doi.org/10.1007/s00344-007-0013-5

2. Tsuchisaka A, Yu G, Jin $\mathrm{H}$ et al (2009) A combinatorial interplay among the 1aminocyclopropane-1-carboxylate isoforms regulates ethylene biosynthesis in Arabidopsis thaliana. Genetics 183:979-1003 https:/doi.org/10.1534/genetics.109. 107102 
3. Arraes FBM, Beneventi MA, Lisei de Sa ME et al (2015) Implications of ethylene biosynthesis and signaling in soybean drought stress tolerance. BMC Plant Biol 15:213 https://doi.org/10.1186/s12870-015-0597-z

4. O'Donnell PJ, Calvert C, Atzorn R, et al (1996) Ethylene as a signal mediating the wound response of tomato plants. Science (80- ) 274:1914-1917. https://doi.org/10.1126/science.274.5294.1914

5. Grichko VP, Glick BR (2001) Ethylene and flooding stress in plants. Plant Physiol Biochem 39:1-9. https://doi.org/10.1016/S0981-9428(00)01213-4

6. Abeles FB, Morgan PW, Saltveit ME (1992) Ethylene in plant biology. Academic Press

7. Lorenzo O, Piqueras R, Sánchez-Serrano JJ, Solano R (2003) ETHYLENE RESPONSE FACTOR1 integrates signals from ethylene and jasmonate pathways in plant defense. Plant Cell 15:165-178 https://doi.org/10.1105/ tpc.007468

8. Miller M, Song $\mathrm{Q}$, Shi $\mathrm{X}$ et al (2015) Natural variation in timing of stressresponsive gene expression predicts heterosis in intraspecific hybrids of Arabidopsis. Nat Commun 6:7453 https://doi.org/10.1038/ncomms8453

9. Guo H, Ecker JR (2004) The ethylene signaling pathway: new insights. Curr Opin Plant Biol 7:40-49

10. Yin $\mathrm{C}-\mathrm{C}, \mathrm{Zhao} \mathrm{H}, \mathrm{Ma} B$ et al (2017) Diverse roles of ethylene in regulating agronomic traits in rice. Front Plant Sci 8:1676 https://doi.org/10.3389/fpls. 2017.01676

11. Bleecker AB, Kende $H$ (2000) Ethylene: A gaseous signal molecule in plants. Annu Rev Cell Dev Biol 16:1-18 https://doi.org/10.1146/annurev.cellbio.16.1.1

12. Dong JG, Fernandez-Maculet JC, Yang SF (1992) Purification and characterization of 1-aminocyclopropane-1-carboxylate oxidase from apple fruit. Proc Natl Acad Sci 89:9789-9793 https://doi.org/10.1073/pnas.89.20.9789

13. Yang SF, Hoffman NE (1984) Ethylene biosynthesis and its regulation in higher plants. Annu Rev Plant Physiol 35:155-189 https://doi.org/10.1146/ annurev.pp.35.060184.001103

14. Jakubowicz M (2002) Structure, catalytic activity and evolutionary relationships of 1-aminocyclopropane-1-carboxylate synthase, the key enzyme of ethylene synthesis in higher plants. Acta Biochim Pol 49:757-774 https://doi.org/024903757

15. Song Q, Ando A, Xu D et al (2018) Diurnal down-regulation of ethylene biosynthesis mediates biomass heterosis. Proc Natl Acad Sci 115:5606-5611 https://doi.org/10.1073/pnas.1722068115

16. Giovannoni J (2001) Molecular biology of fruit maturation and ripening. Annu Rev Plant Physiol Plant Mol Biol 52:725-749 https://doi.org/10.1146/ annurev.arplant.52.1.725

17. Alexander L, Grierson D (2002) Ethylene biosynthesis and action in tomato: a model for climacteric fruit ripening. J Exp Bot 53:2039-2055 https://doi. org/10.1093/jxb/erf072

18. Yamagami T, Tsuchisaka A, Yamada K et al (2003) Biochemical diversity among the 1-amino-cyclopropane-1-carboxylate synthase isozymes encoded by the Arabidopsis gene family. J Biol Chem 278:49102-49112 https://doi.org/10.1074/jbc.M308297200

19. Chae HS, Kieber JJ (2005) Eto Brute? Role of ACS turnover in regulating ethylene biosynthesis. Trends Plant Sci 10:291-296 https://doi.org/10.1016/j. tplants.2005.04.006

20. Lee HY, Yoon GM (2018) Regulation of ethylene biosynthesis by phytohormones in etiolated rice (Oryza sativa L.) seedlings. Mol Cell 41:311$319 \mathrm{https} / / /$ doi.org/10.14348/molcells.2018.2224

21. Sebastià CH, Hardin SC, Clouse SD et al (2004) Identification of a new motif for CDPK phosphorylation in vitro that suggests ACC synthase may be a CDPK substrate. Arch Biochem Biophys 428:81-91 https://doi.org/10.1016/j. abb.2004.04.025

22. Kim CY, Liu Y, Thorne ET et al (2003) Activation of a stress-responsive mitogenactivated protein kinase cascade induces the biosynthesis of ethylene in plants. Plant Cell 15:2707-2718 https://doi.org/10.1105/tpc.011411

23. Liu Y, Zhang S (2004) Phosphorylation of 1-aminocyclopropane-1-carboxylic acid synthase by MPK6, a stress-responsive mitogen-activated protein kinase, induces ethylene biosynthesis in Arabidopsis. Plant Cell 16:33863399 https://doi.org/10.1105/tpc.104.026609

24. Yoon GM (2015) New insights into the protein turnover regulation in ethylene biosynthesis. Mol Cell 38:597-603 https://doi.org/10.14348/ molcells.2015.0152

25. Chae HS, Faure F, Kieber JJ (2003) The eto1, eto2, and eto3 mutations and cytokinin treatment increase ethylene biosynthesis in Arabidopsis by increasing the stability of ACS protein. Plant Cell 15:545-559 https://doi.org/ $10.1105 /$ tpc.006882
26. Christians MJ, Gingerich DJ, Hansen M et al (2009) The BTB ubiquitin ligases ETO1, EOL1 and EOL2 act collectively to regulate ethylene biosynthesis in Arabidopsis by controlling type-2 ACC synthase levels. Plant J 57:332-345 https://doi.org/10.1111/j.1365-313X.2008.03693.x

27. Wang KL-C, Yoshida H, Lurin C, Ecker JR (2004) Regulation of ethylene gas biosynthesis by the Arabidopsis ETO1 protein. Nature 428:945-950 https:// doi.org/10.1038/nature02516

28. Yoshida H, Nagata M, Saito K et al (2005) Arabidopsis ETO1 specifically interacts with and negatively regulates type 21 -aminocyclopropane-1carboxylate synthases. BMC Plant Biol 5:14 https://doi.org/10.1186/14712229-5-14

29. Sasaki T, Matsumoto T, Antonio B, Nagamura Y (2005) From mapping to sequencing, post-sequencing and beyond. Plant Cell Physiol 46:3-13 https://doi.org/10.1093/pcp/pci503

30. Du H, Yu Y, Ma Y et al (2017) Sequencing and de novo assembly of a near complete indica rice genome. Nat Commun 8:15324 https://doi.org/10. 1038/ncomms15324

31. Sahi C, Singh A, Kumar K et al (2006) Salt stress response in rice: genetics, molecular biology, and comparative genomics. Funct Integr Genomics 6: 263-284 https://doi.org/10.1007/s10142-006-0032-5

32. Iwamoto M, Baba-kasai A, Kiyota S et al (2010) ACO1, a gene for aminocyclopropane-1-carboxylate oxidase: effects on internode elongation at the heading stage in rice. Plant Cell Environ 33:805-815 https://doi.org/ 10.1111/j.1365-3040.2009.02106.x

33. Mekhedov SL, Kende H (1996) Submergence enhances expression of a gene encoding 1-aminocyclopropane-1-carboxylate oxidase in deepwater rice. Plant Cell Physiol 37:531-537 https://doi.org/10.1093/oxfordjournals.pcp. a028976

34. Chae HS, Cho YG, Park MY et al (2000) Hormonal cross-talk between auxin and ethylene differentially regulates the expression of two members of the 1-aminocyclopropane-1-carboxylate oxidase gene family in rice (Oryza sativa L.). Plant Cell Physiol 41:354-362 https://doi.org/10.1093/pcp/41.3.354

35. Ferrari S, Vairo D, Ausubel FM et al (2003) Tandemly duplicated Arabidopsis genes that encode polygalacturonase-inhibiting proteins are regulated coordinately by different signal transduction pathways in response to fungal infection. Plant Cell 15:93-106 https://doi.org/10.1105/tpc.005165

36. Thomma BPHJ, Eggermont K, Tierens KFM-J, Broekaert WF (1999) Requirement of functional ethylene-insensitive 2 gene for efficient resistance of Arabidopsis to infection by Botrytis cinerea. Plant Physiol 121: 1093-1101 https://doi.org/10.1104/pp.121.4.1093

37. Pré $M$, Atallah M, Champion A et al (2008) The AP2/ERF domain transcription factor ORA59 integrates jasmonic acid and ethylene signals in plant defense. Plant Physiol 147:1347-1357 https://doi.org/10.1104/pp.108. 117523

38. Berrocal-Lobo M, Molina A, Solano R (2002) Constitutive expression of ETHY LENE-RESPONSE-FACTOR1 in Arabidopsis confers resistance to several necrotrophic fungi. Plant J 29:23-32

39. Berrocal-Lobo M, Molina A (2004) Ethylene response factor 1 mediates Arabidopsis resistance to the soilborne fungus Fusarium oxysporum. Mol PlantMicrobe Interact 17:763-770 https://doi.org/10.1094/MPMI.2004.17.7.763

40. Schweighofer A, Kazanaviciute V, Scheikl E et al (2007) The PP2C-type phosphatase AP2C1, which negatively regulates MPK4 and MPK6, modulates innate immunity, jasmonic acid, and ethylene levels in Arabidopsis. Plant Cell 19:2213-2224 https://doi.org/10.1105/tpc.106.049585

41. Cao W-H, Liu J, He X-J et al (2007) Modulation of ethylene responses affects plant salt-stress responses. Plant Physiol 143:707-719 https://doi.org/10. 1104/pp.106.094292

42. Peng J, Li Z, Wen X et al (2014) Salt-induced stabilization of EIN3/EIL1 confers salinity tolerance by deterring ROS accumulation in Arabidopsis. PLoS Genet 10:e1004664 https://doi.org/10.1371/journal.pgen.1004664

43. Tao J-J, Chen H-W, Ma B et al (2015) The role of ethylene in plants under salinity stress. Front Plant Sci 6:1059 https://doi.org/10.3389/fpls.2015.01059

44. Linkies A, Leubner-Metzger G (2012) Beyond gibberellins and abscisic acid: how ethylene and jasmonates control seed germination. Plant Cell Rep 31: 253-270 https://doi.org/10.1007/s00299-011-1180-1

45. Matilla AJ, Matilla-Vázquez MA (2008) Involvement of ethylene in seed physiology. Plant Sci 175:87-97 https://doi.org/10.1016/J.PLANTSCI.2008.01.014

46. Pegoraro C, Farias D da R, Mertz LM et al (2013) Ethylene response factors gene regulation and expression profiles under different stresses in rice. Theor Exp Plant Physiol 25:261-274 https://doi.org/10.1590/S219700252013000400004 
47. Yu Y, Wang J, Zhang Z et al (2013) Ethylene promotes hypocotyl growth and HY5 degradation by enhancing the movement of COP1 to the nucleus in the light. PLoS Genet 9:e1004025 https://doi.org/10.1371/journal.pgen. 1004025

48. Hattori Y, Nagai K, Furukawa S et al (2009) The ethylene response factors SNORKEL1 and SNORKEL2 allow rice to adapt to deep water. Nature 460: 1026-1030 https://doi.org/10.1038/nature08258

49. Zhong S, Shi H, Xue C et al (2012) A molecular framework of lightcontrolled phytohormone action in Arabidopsis. Curr Biol 22:1530-1535 https://doi.org/10.1016/j.cub.2012.06.039

50. Shi H, Shen X, Liu R et al (2016) The red light receptor phytochrome B directly enhances substrate-E3 ligase interactions to attenuate ethylene responses. Dev Cell 39:597-610 https://doi.org/10.1016/j.devcel.2016.10.020

51. Shi H, Liu R, Xue C et al (2016) Seedlings transduce the depth and mechanical pressure of covering soil using COP1 and ethylene to regulate EBF1/EBF2 for soil emergence. Curr Biol 26:139-149 https://doi.org/10.1016/ j.cub.2015.11.053

52. Sun J, Ma Q, Mao T (2015) Ethylene regulates the Arabidopsis microtubuleassociated protein WAVE-DAMPENED2-LIKE5 in etiolated hypocotyl elongation. Plant Physiol 169:325-337 https://doi.org/10.1104/pp.15.00609

53. Osterlund MT, Hardtke CS, Wei N, Deng XW (2000) Targeted destabilization of HY5 during light-regulated development of Arabidopsis. Nature 405:462466 https://doi.org/10.1038/35013076

54. Harpaz-Saad S, Yoon GM, Mattoo AK, Kieber JJ (2012) The formation of ACC and competition between polyamines and ethylene for SAM. In: Annual Plant Reviews Volume 44. Wiley-Blackwell, Oxford, UK, pp 53-81

55. Yoon GM, Kieber JJ (2013) 14-3-3 regulates 1-aminocyclopropane-1carboxylate synthase protein turnover in Arabidopsis. Plant Cell 25:10161028 https://doi.org/10.1105/tpc.113.110106

56. Kawahara Y, de la Bastide M, Hamilton JP et al (2013) Improvement of the Oryza sativa Nipponbare reference genome using next generation sequence and optical map data. Rice 6:4 https://doi.org/10.1186/1939-8433-6-4

57. Gasteiger E, Hoogland C, Gattiker A et al (2005) Protein identification and analysis tools on the ExPASy server. In: The Proteomics Protocols Handbook. Humana Press, Totowa, NJ, pp 571-607

58. Waterhouse A, Bertoni M, Bienert S et al (2018) SWISS-MODEL: Homology modelling of protein structures and complexes. Nucleic Acids Res 46:W296W303 https://doi.org/10.1093/nar/gky427

59. Hruz T, Laule O, Szabo G et al (2008) Genevestigator v3: a reference expression database for the meta-analysis of transcriptomes. Adv Bioinforma 2008:420747 https://doi.org/10.1155/2008/420747

60. Dai X, Zhuang Z, Zhao PX (2018) psRNATarget: a plant small RNA target analysis server (2017 release). Nucleic Acids Res 46:W49-W54 https://doi. org/10.1093/nar/gky316

61. Chow C-N, Zheng H-Q, Wu N-Y et al (2016) PlantPAN 2.0: an update of plant promoter analysis navigator for reconstructing transcriptional regulatory networks in plants. Nucleic Acids Res 44:D1154-D1160 https:// doi.org/10.1093/nar/gkv1035

62. Gupta R, Brunak S (2002) Prediction of glycosylation across the human proteome and the correlation to protein function. Pac Symp Biocomput: 310-322

63. Blom N, Gammeltoft S, Brunak S (1999) Sequence and structure-based prediction of eukaryotic protein phosphorylation sites. J Mol Biol 294:13511362 https://doi.org/10.1006/jmbi.1999.3310

64. Elliott RC, Betzner AS, Huttner E et al (1996) AINTEGUMENTA, an APETALA2like gene of Arabidopsis with pleiotropic roles in ovule development and floral organ growth. Plant Cell 8:155-168 https://doi.org/10.1105/tpc.8.2.155

65. Boutilier $\mathrm{K}$, Offringa R, Sharma VK et al (2002) Ectopic expression of BABY BOOM triggers a conversion from vegetative to embryonic growth. Plant Cell 14:1737-1749 https://doi.org/10.1105/tpc.001941

66. Vahala J, Felten J, Love J et al (2013) A genome-wide screen for ethyleneinduced ethylene response factors (ERFs) in hybrid aspen stem identifies ERF genes that modify stem growth and wood properties. New Phytol 200: 511-522 https://doi.org/10.1111/nph.12386

67. Cheng M-C, Liao P-M, Kuo W-W, Lin T-P (2013) The Arabidopsis ETHYLENE RESPONSE FACTOR1 regulates abiotic stress-responsive gene expression by binding to different cis-acting elements in response to different stress signals. Plant Physiol 162:1566-1582 https://doi.org/10.1104/pp.113.221911

68. Xu K, Xu X, Fukao T et al (2006) Sub1A is an ethylene-response-factor-like gene that confers submergence tolerance to rice. Nature 442:705-708 https://doi.org/10.1038/nature04920
69. Yamamoto S, Suzuki K, Shinshi H (1999) Elicitor-responsive, ethyleneindependent activation of GCC box-mediated transcription that is regulated by both protein phosphorylation and dephosphorylation in cultured tobacco cells. Plant J 20:571-579

70. Jiao Y, Ma L, Strickland E, Deng XW (2005) Conservation and divergence of light-regulated genome expression patterns during seedling development in rice and Arabidopsis. Plant Cell 17:3239-3256 https://doi.org/10.1105/tpc. 105.035840

71. Maruyama-Nakashita A, Nakamura Y, Watanabe-Takahashi A et al (2005) Identification of a novel cis-acting element conferring sulfur deficiency response in Arabidopsis roots. Plant J 42:305-314 https://doi.org/10.1111/j. 1365-313X.2005.02363.x

72. Simpson SD, Nakashima K, Narusaka $Y$ et al (2003) Two different novel cisacting elements of erd1, a clpA homologous Arabidopsis gene function in induction by dehydration stress and dark-induced senescence. Plant J 33: $259-270$

73. Johnson C, Boden E, Arias J (2003) Salicylic acid and NPR1 induce the recruitment of trans-activating TGA factors to a defense gene promoter in Arabidopsis. Plant Cell 15:1846-1858 https://doi.org/10.1105/tpc.012211

74. Ko J-H, Beers EP, Han K-H (2006) Global comparative transcriptome analysis identifies gene network regulating secondary xylem development in Arabidopsis thaliana. Mol Gen Genomics 276:517-531 https://doi.org/10. 1007/s00438-006-0157-1

75. Wang ZY, Kenigsbuch D, Sun L et al (1997) A Myb-related transcription factor is involved in the phytochrome regulation of an Arabidopsis Lhcb gene. Plant Cell 9:491-507 https://doi.org/10.1105/tpc.9.4.491

76. Mohanty B, Krishnan SPT, Swarup S, Bajic VB (2005) Detection and preliminary analysis of motifs in promoters of anaerobically induced genes of different plant species. Ann Bot 96:669-681 https://doi.org/10.1093/aob/mci219

77. Kosugi S, Suzuka I, Ohashi Y (1995) Two of three promoter elements identified in a rice gene for proliferating cell nuclear antigen are essential for meristematic tissue-specific expression. Plant J 7:877-886

78. Luo H, Song F, Goodman RM, Zheng Z (2005) Up-regulation of OsBIHD1, a rice gene encoding BELL homeodomain transcriptional factor, in disease resistance responses. Plant Biol 7:459-468 https://doi.org/10.1055/s-2005-865851

79. Hwang YS, Karrer EE, Thomas BR et al (1998) Three cis-elements required for rice alpha-amylase Amy3D expression during sugar starvation. Plant $\mathrm{Mol}$ Biol 36:331-341

80. Kosugi S, Ohashi Y (2002) E2F sites that can interact with E2F proteins cloned from rice are required for meristematic tissue-specific expression of rice and tobacco proliferating cell nuclear antigen promoters. Plant J 29:45-59

81. Sutoh K, Yamauchi D (2003) Two cis-acting elements necessary and sufficient for gibberellin-upregulated proteinase expression in rice seeds. Plant J 34:635-645

82. Heidari P, Ahmadizadeh M, Izanlo F, Nussbaumer T (2019) In silico study of the CESA and CSL gene family in Arabidopsis thaliana and Oryza sativa: Focus on post-translation modifications. Plant Gene 19. https://doi.org/10. 1016/j.plgene.2019.100189

83. Bigeard J, Rayapuram N, Pflieger D, Hirt H (2014) Phosphorylationdependent regulation of plant chromatin and chromatin-associated proteins. Proteomics 14:2127-2140 https://doi.org/10.1002/pmic.201400073

84. Heyl A, Brault M, Frugier F et al (2013) Nomenclature for members of the two-component signaling pathway of plants. Plant Physiol 161:1063-1065 https://doi.org/10.1104/pp.112.213207

85. Osakabe Y, Yamaguchi-Shinozaki K, Shinozaki K, Tran L-SP (2013) Sensing the environment: key roles of membrane-localized kinases in plant perception and response to abiotic stress. J Exp Bot 64:445-458 https://doi. org/10.1093/jxb/ers354

86. Friso G, van Wijk KJ (2015) Update: Post-translational protein modifications in plant metabolism. Plant Physiol 01378(2015) https://doi.org/10.1104/pp. 15.01378

87. Bidonde S, Ferrer MA, Zegzouti $\mathrm{H}$ et al (1998) Expression and characterization of three tomato 1-aminocyclopropane-1-carboxylate oxidase cDNAs in yeast. Eur J Biochem 253:20-26 https://doi.org/10.1046/j. 1432-1327.1998.2530020.x

88. Kyte J, Doolittle RF (1982) A simple method for displaying the hydropathic character of a protein. J Mol Biol 157:105-132

89. Heidari P, Mazloomi F, Nussbaumer T, Barcaccia G (2020) Insights into the SAM synthetase gene family and its roles in tomato seedlings under abiotic stresses and hormone treatments. Plants 9. https://doi.org/10.3390/ plants9050586 
90. Ikai A (1980) Thermostability and aliphatic index of globular proteins. J Biochem 88:1895-1898

91. Bachmair A, Finley D, Varshavsky A (1986) In vivo half-life of a protein is a function of its amino-terminal residue. Science 234:179-186

92. Roche DB, Brackenridge DA, McGuffin $L$ (2015) Proteins and their interacting partners: An introduction to protein-ligand binding site prediction methods. Int J Mol Sci 16:29829-29842

93. Dukka BKC (2013) Structure-based methods for computational protein functional site prediction. Comput Struct Biotechnol J 8:e201308005

94. Ezzat A, Kwoh CK (2012) Comparison of structure-based tools for the prediction of ligand binding site residues in apo-structures. Procedia Computer Science. Elsevier B.V, In, pp 115-126

95. Abrusán G, Marsh JA (2018) Ligand binding site structure influences the evolution of protein complex function and topology. Cell Rep 22:3265-3276 https://doi.org/10.1016/j.celrep.2018.02.085

96. Alonso JM, Stepanova AN (2004) The ethylene signaling pathway. Science (80- ) 306:1513-1515. https://doi.org/10.1126/science.1104812

97. Liu C, Lü R, Li J et al (2014) Characterization and expression profiles of MaACS and MaACO genes from mulberry (Morus alba L.). J Zhejiang Univ B 15:611-623 https://doi.org/10.1631/jzus.B1300320

98. Tsuchisaka A, Theologis A (2004) Unique and overlapping expression patterns among the Arabidopsis 1-amino-cyclopropane-1-carboxylate synthase gene family members. Plant Physiol 136:2982-3000 https://doi.org/ 10.1104/pp.104.049999

99. Wang NN, Shih M-C, Li N (2005) The GUS reporter-aided analysis of the promoter activities of Arabidopsis ACC synthase genes AtACS4, AtACS5, and AtACS7 induced by hormones and stresses. J Exp Bot 56:909-920 https:// doi.org/10.1093/jxb/eri083

100. Zarembinski TI, Theologis A (1994) Ethylene biosynthesis and action: a case of conservation. Plant Mol Biol 26:1579-1597

101. Olson DC, White JA, Edelman L et al (1991) Differential expression of two genes for 1-aminocyclopropane-1-carboxylate synthase in tomato fruits. Proc Natl Acad Sci U S A 88:5340-5344 https://doi.org/10.1073/pnas.88.12. 5340

102. Lincoln JE, Campbell AD, Oetiker J et al (1993) LE-ACS4, a fruit ripening and wound-induced 1-aminocyclopropane-1-carboxylate synthase gene of tomato (Lycopersicon esculentum). Expression in Escherichia coli, structural characterization, expression characteristics, and phylogenetic analysis. J Biol Chem 268:19422-19430

103. Rottmann WH, Peter GF, Oeller PW, et al (1991) 1-Aminocyclopropane-1carboxylate synthase in tomato is encoded by a multigene family whose transcription is induced during fruit and floral senescence. J Mol Biol 222: 937-961. https://doi.org/10.1016/0022-2836(91)90587-V

104. Lelièvre JM, Tichit L, Dao P et al (1997) Effects of chilling on the expression of ethylene biosynthetic genes in Passe-Crassane pear (Pyrus communis L.) fruits. Plant Mol Biol 33:847-855

105. Arteca JM, Arteca RN (1999) A multi-responsive gene encoding 1aminocyclopropane-1-carboxylate synthase (ACS6) in mature Arabidopsis leaves. Plant Mol Biol 39:209-219

106. Peng H-P, Lin T-Y, Wang N-N, Shih M-C (2005) Differential expression of genes encoding 1-aminocyclopropane-1-carboxylate synthase in Arabidopsis during hypoxia. Plant Mol Biol 58:15-25 https://doi.org/10.1007/ s11103-005-3573-4

107. Ahmadizadeh M, Heidari P (2014) Bioinformatics study of transcription factors involved in cold stress. Biharean Biol 8:83-86

108. Rezaee S, Ahmadizadeh M, Heidari P (2020) Genome-wide characterization, expression profiling, and post- transcriptional study of GASA gene family. Gene Reports 20:100795 https://doi.org/10.1016/j.genrep.2020.100795

109. Ibraheem O, Botha CEJ, Bradley G (2010) In silico analysis of cis-acting regulatory elements in $5^{\prime}$ regulatory regions of sucrose transporter gene families in rice (Oryza sativa Japonica) and Arabidopsis thaliana. Comput Biol Chem 34:268-283 https://doi.org/10.1016/j.compbiolchem.2010.09.003

110. Moldovan D, Spriggs A, Yang J et al (2010) Hypoxia-responsive microRNAs and trans-acting small interfering RNAs in Arabidopsis. J Exp Bot 61:165-177 https://doi.org/10.1093/jxb/erp296

111. Zhu Q-H, Spriggs A, Matthew L et al (2008) A diverse set of microRNAs and microRNA-like small RNAs in developing rice grains. Genome Res 18:14561465 https://doi.org/10.1101/gr.075572.107

112. Rhoades MW, Reinhart BJ, Lim LP, et al (2002) Prediction of plant microRNA targets. Cell 110:513-520. https://doi.org/10.1016/s0092-8674(02)00863-2
113. van Wijk KJ, Friso G, Walther D, Schulze WX (2014) Meta-analysis of Arabidopsis thaliana phospho-proteomics data reveals compartmentalization of phosphorylation motifs. Plant Cell 26:2367-2389 https://doi.org/10.1105/tpc.114.125815

114. Schönberg A, Baginsky S (2012) Signal integration by chloroplast phosphorylation networks: an update. Front Plant Sci 3:256 https://doi.org/ 10.3389/fpls.2012.00256

115. Silva-Sanchez C, Li H, Chen S (2015) Recent advances and challenges in plant phosphoproteomics. Proteomics 15:1127-1141 https://doi.org/10. 1002/pmic.201400410

116. Kamiyoshihara Y, Iwata M, Fukaya T, et al (2010) Turnover of LeACS2, a wound-inducible 1-aminocyclopropane-1-carboxylic acid synthase in tomato, is regulated by phosphorylation/dephosphorylation. Plant J 64:nono. https://doi.org/10.1111/j.1365-313X.2010.04316.x

117. Tatsuki M, Mori H (2001) Phosphorylation of tomato 1-aminocyclopropane1-carboxylic acid synthase, LE-ACS2, at the C-terminal region. J Biol Chem 276:28051-28057 https://doi.org/10.1074/jbc.M101543200

118. Solá RJ, Griebenow K (2009) Effects of glycosylation on the stability of protein pharmaceuticals. J Pharm Sci 98:1223-1245 https://doi.org/10.1002/ jps.21504

119. Hamilton SR, Gerngross TU (2007) Glycosylation engineering in yeast: the advent of fully humanized yeast. Curr Opin Biotechnol 18:387-392 https:// doi.org/10.1016/j.copbio.2007.09.001

\section{Publisher's Note}

Springer Nature remains neutral with regard to jurisdictional claims in published maps and institutional affiliations.

\section{Submit your manuscript to a SpringerOpen ${ }^{\circ}$ journal and benefit from:}

- Convenient online submission

- Rigorous peer review

- Open access: articles freely available online

High visibility within the field

- Retaining the copyright to your article

Submit your next manuscript at $>$ springeropen.com 